\begin{tabular}{|c|c|}
\hline \multirow[t]{4}{*}{ Citation } & Charles Onyutha, Agnieszka Rutkowska, Paul Nyeko-Ogiramoi, Patrick \\
\hline & Willems, (2019), \\
\hline & $\begin{array}{l}\text { How well do climate models reproduce variability in observed rainfall? A } \\
\text { case study of the Lake Victoria basin considering CMIP3, CMIP5 and } \\
\text { CORDEX simulations }\end{array}$ \\
\hline & $\begin{array}{l}\text { STOCHASTIC ENVIRONMENTAL RESEARCH AND RISK ASSESSMENT, } \\
\text { 33(3), 687-707. }\end{array}$ \\
\hline Archived version & $\begin{array}{l}\text { Author manuscript: the content is identical to the content of the published } \\
\text { paper, but without the final typesetting by the publisher }\end{array}$ \\
\hline Published version & https://link.springer.com/article/10.1007/s00477-018-1611-4 \\
\hline Journal homepage & $\underline{\text { https://www.springer.com/journal/477 }}$ \\
\hline Author contact & Patrick.Willems@kuleuven.be \\
\hline IR & https://lirias2.kuleuven.be/viewobject.html?cid=1\&id=2242958 \\
\hline
\end{tabular}

(article begins on next page) 


\section{How well do climate models reproduce variability in observed rainfall? A case study of the Lake Victoria basin considering CMIP3, CMIP5 and CORDEX simulations}

Charles Onyutha ${ }^{* 1,2}$, Agnieszka Rutkowska ${ }^{3}$, Paul Nyeko-Ogiramoi ${ }^{4}$, Patrick Willems $^{1,5}$

${ }^{1}$ KU Leuven, Hydraulics Section, B-3001 Leuven, Belgium

${ }^{2}$ Faculty of Technoscience, Muni University, P.O Box 725, Arua, Uganda

${ }^{3}$ University of Agriculture, Department of Applied Mathematics, Kraków, Poland

${ }^{4}$ Rural Water and Sanitation Department, Ministry of Water and Environment, 22/28 Port Bell Road, Luzira, P.O Box 200026, Kampala, Uganda

${ }^{5}$ Vrije Universiteit Brussel, Department of Hydrology and Hydraulic Engineering, 1050 Elsene, Brussel, Belgium

*E-Mail: conyutha@gmail.com

\section{Abstract:}

In this study, how well the climate models reproduce variability in observed rainfall was assessed based on General Circulation Models (GCMs) from phase 3 and phase 5 of the Coupled Model Inter-comparison Project, i.e. CMIP3 and CMIP5, respectively as well as the Regional Climate Models (RCMs) of Coordinated Regional Climate Downscaling Experiment (CORDEX) over Africa. Observed and climate model based daily rainfall across the Lake Victoria Basin, which is one of the wettest parts of Africa, was considered. Temporal variability was assessed based on the coefficient of variation of daily and annual rainfall, and the maximum dry and wet spell in each year. Furthermore, variation in daily rainfall was assessed in terms of the long-range dependence. Comparison of variability results from observed and climate model based rainfall was made. It was found that the capacity to reproduce variability in observed wet and dry conditions depends on the specific GCM (of CMIP3 or CMIP5) or CORDEX RCM. However, the CORDEX RCMs replicated variability in observed daily rainfall better than the CMIP3 and CMIP5 GCMs. This was due to the spatial resolutions of the CORDEX RCMs which are higher than those of the CMIP3 and CMIP5 GCMs. The ensemble mean of the coefficients of correlation between the variability in observed and that of climate model based rainfall were close to zero for both the GCMs or RCMs. This suggests that analyses can be done on a case by case basis. In other words, 
GCMs or RCMs which adequately reproduce variability in observed wet and dry conditions can be considered for further statistical analysis of the changes especially on the basis of statistical methods for downscaling. For daily timescale, both the GCMs and RCMs from all the three sets of climate models generally exhibited poor performance in capturing the time of occurrences and the magnitudes of rainfall events (when considered in a combined way). To reliably assess long-term rainfall changes, it is vital to characterize natural variation in terms of the statistical dependence. With respect to natural variability of rainfall at local scales, there is room for further improvement of the climate models; however, whether theory of fractals and/or concepts of scaling behavior or self-similarity can explicitly contribute in that respect is a crucial consideration. Results from this study gave some insights in the reasonableness of the future rainfall projections.

Keywords: CMIP3; CMIP5; CORDEX; Climate change; Climate Variability; GCM; RCM; Lake Victoria; Rainfall variability

\section{Introduction}

The continued increase in greenhouse gas emissions is responsible for the warming and changes in all components of the climate system (Intergovernmental Panel on Climate Change, IPCC 2013). Eventually, the need for research on climate change has greatly attracted attention of the scientific community. Examples of recent studies on climate change include Ciu et al. (2018), Mohammed et al. (2018), Almasi et al. (2017), Oguntunde et al. (2017), Wu et al. (2017), Kim et al. (2016), Onyutha et al. (2016), Wu et al. (2016), Ouyang et al. (2015). Apart from the focus on climate change, considerable attention of researchers is also geared towards climate variability; see, for instance, studies by Roushangar et al. (2018), Onyutha (2018a), Li et al. 
(2018), Nkiaka et al. (2017), Onyutha and Willems (2017), and Rutkowska et al. (2017). Whereas variation inherent in the stationary stochastic process approximating the climate on scale of a few decades comprises climate variability (World Meteorological Organization, 1988), climate change requires the consideration of long-term periods, preferably 30 years and above. One key research area has been the simulation of the response of the global climate system to the increasing greenhouse gas concentrations. For such a simulation, General Circulation Models (GCMs) are the most advanced contemporary tools used. The GCMs represent the physical processes in the atmosphere, ocean, cryosphere and land surfaces. According to the Data Distribution Center (DDC 2015), to depict the climate, the GCMs make use of a three dimensional grid over the globe typically having 10 to 20 vertical layers in the atmosphere (as many as 30 layers in the oceans) and a horizontal resolution of between 250 and $600 \mathrm{~km}$. Actually, the spatial resolutions of the GCMs are quite coarse. To address some of the problems due to the coarse spatial scale of the GCMs, the spatial resolution of the Coordinated Regional Climate Downscaling Experiment (CORDEX) Regional Circulation Models (RCMs) is greatly refined, for instance, to a grid-spacing as small as $0.44^{\circ}$.

Some of the variables obtained as outputs from the GCMs and RCMs include temperature, rainfall, etc. Generally, among other variables, rainfall is so critical that its changes can be used to obtain an insight into the influence of the climate system on regional hydrology in support of developing reasonable measures to adapt to climate change impacts (Onyutha et al. 2016). To correctly characterize the earth systems, thorough understanding of space-time properties of rainfall is required for models of land surface hydrology, biogeochemistry, and ecology that simulate human systems in a context of global and environmental change (Kaptué et al. 2015). According to Batisani and Yarnal (2010), variability of rainfall makes it difficult to assess contemporary trends in rainfall distributions and potential impacts of climate change. Rainfall time series often exhibit strong variability in time and space (Yu et al. 2014) and this comprises a central characteristic of the various regions of the world. Furthermore, rainfall exhibits spatio-temporal scaling behavior (see, for instance, Gupta and Waymire 1990; Zhang et al. 2008). Rainfall is known to exhibit self-similarity or fractal behavior (see for instance, Meseguer-Ruiz et al. 2017; Ghanmi et al. 2013). Processes are said to be fractal if they cannot be defined by the classical 
Euclidian mathematics. Regular objects are also referred to as fractal. Insight into the uncertainty due to natural variability can be obtained through the concept of the Hurst phenomenon. The Hurst phenomenon (Hurst 1951) can be attributed to the non-stationary means of the process (Klemeš 1974). However, this is only true if the means can be expressed in a deterministic way as a function of time (Koutsoyiannis 2000). In a long-term series, changes can be characterized by local or short-durational rising and falling trends (also called the sub-trends, Onyutha 2016). The rising and falling trends are large-scale random fluctuations although they would be considered deterministic components if they could be conditioned by a physical explanation and predictability (Koutsoyiannis 2000). These fluctuations are actually indicative of the Hurst phenomenon. Due to its relationship with the climate changes, the Hurst phenomenon is increasingly capturing interests of the climate scientists (Evans 1996).

There are a wide range of physical processes (ranging from climate dynamics to water droplet formation) which control rainfall fluctuations or variability in both space and time (Kiely and Ivanova 1999). The considerable rainfall fluctuations and high variability complicate its statistical and mathematical processing (Meseguer-Ruiz et al. 2017) and modeling. This complexity (for instance, in predicting rainfall variability) is compounded by the nature of the variability drivers. For instance, factors that control rainfall variability in both space and time may considerably differ from those that drive mean conditions. This important aspect of variability was illustrated by Nicholson (2000) in terms of the diversity of climatic controls which was evident from the patterns of rainfall and its seasonality over East Africa (where from, eventually, the study area was selected). However, factors controlling rainfall variability tend to be more coherent than those governing mean climate (Nicholson 2000). It is 
vital to note that by taking more climate dynamics into account, forecasting models which incorporate fractals tend to be considerably reliable on a regional scale (Rangarajan and Sant 1997; 2004). Nevertheless, to adequately characterize rainfall across a region, it is vital to understand the regional climate mechanisms.

With respect to the changes in large-scale ocean-atmosphere conditions, the variation in the Sea Surface Temperature (SST) of the Indian Ocean greatly influences the rainfall over the study area by altering the local Walker circulation. However, rainfall over East Africa (where the study area is located) is also, to some extent, shaped by the variation in the SSTs from the Pacific Ocean and Sea Level Pressure over the Atlantic Ocean (Onyutha 2018a). According to Indeje et al. (2000), the short rains over most of the East African region are associated with El Niño Southern Oscillation.

With respect to the general circulation, over the Equatorial region (where the study area is located), rainfall is controlled by two airstreams and three convergence zones (Trewartha 1981; Nicholson 1996). The airstreams include the humid Congo airstream with Westerly and the Southwesterly flow, and the relatively dry Northeast and Southeast monsoons. The convergence zones include the Congo Air boundary and the Inter-Tropical Convergence Zone (ITCZ). The third convergence zone is that which separates the moist Southerly flow and the dry, stable, Northerly flow of Saharan origin. Both the convergence zones and airstreams shift seasonally.

With respect to airstreams, by July/August, the upper-level flow is Easterly over most of the African continent (Nicholson 2000). The Easterlies comprise majorly the African Easterly Jet (AEJ), and the Tropical Easterly Jet (TEJ) and these jets control the development of the summer precipitation regime North of the study area (especially over Northern Africa). In West Africa most of the precipitation emanates from the Easterly waves. Apart from AEJ and TEJ, a small Easterly also exists maximum at about $10^{\circ} \mathrm{S}$. The Westerlies prevail over the temperate extremes of the African continent (Nicholson 2000). The frequency of these Westerlies increases by January. Rainfall over the study area is also influenced by the quasi-periodic oscillation of the Equatorial zonal wind between Easterlies and Westerlies in the tropical stratosphere with an average 
period from 28 to 29 months (Indeje et al. 2000). South of the Lake Victoria, diverging South-Easterly winds from the Indian Ocean induce dry conditions (Camberlin 2009). Furthermore, the seasonal climate of East Africa is also modified by the Northeast and Southeast monsoon winds (Mukabana and Piekle 1996).

Regarding the shifts in convergence zones, at the beginning of the year (in January), pressure is high over the Sahara. However, the Southern part of the African continent is characterized by low pressure. The ITCZ exists far South of the Equator. Slightly past mid of the year (July or August), low and high pressures exist over Sahara and the Southern Africa, respectively. The ITCZ has moved North of the Equator, as far as close to $20^{\circ} \mathrm{N}$ thereby separating the North East trade winds and the South West monsoon flow. In summary, by the beginning (mid) of the year, the convergence zones exist in the Southern (Northern) hemisphere. Important to note is that, from September, the ITCZ retreats to the South faster than its Northward shift (Osman and Hastenrath 1969). The precipitation pattern and distribution across Africa dominantly rely the migration of the ITCZ. A band of precipitation moves with the ITCZ as it migrates from its most Southern location (in January) to the Northern extreme (by July). Around the Equator, where the ITCZ passes twice in a year, precipitation is of bimodal pattern characterized by short and long rainy seasons in the March-to-May and October-to-December periods, respectively. However, North of the Equator, the precipitation is of a unimodal pattern with the peak occurring during the summer (June-to-September) season.

With respect to the regional and local factors, in the Equatorial region, influences on the ITCZ come from regional topographical features such as large water bodies (like the Lake Victoria), and high mountains (including Mount 
Elgon, Mount Rwenzori, and Mount Kenya) (Onyutha et al. 2016). According to Camberlin (2009), some of the Great Lakes of East Africa also tend to develop their own circulation. This is through lake breezes induced by the small diurnal temperature variations of the lakes compared to the surrounding areas. Especially for the Lake Victoria, its circular geometry encourages daytime breezes diverging from the lake to the warmer surrounding land, and night-time land breezes converging to the warmer middle part of the lake (Fraedrich 1972; Camberlin 2009). Mountain ranges also set up their own circulation and generate their own climate (Camberlin 2009). Especially around the Lake Victoria, there also exists the slope circulation, especially to the Northeast of the lake which is bordered by the Western Kenya Highlands (Okeyo 1987). The joint effect of lake and upslope breezes enhances afternoon convection (Camberlin 2009). The Great Lakes and high mountains greatly influence the atmospheric dynamics and stability with respect to the East African regional climate.

With the refinement of spatial resolution and other improvements of climate models, the ability of the models to represent regional and/or local impacts of global climate phenomenon (for instance, El Niño Southern Oscillation) is expected to increase. However, if: (i) the models still have reduced capacity to represent key processes at the local scale, and (ii) there exists considerable data quality problems (such as errors stemming from observation or recording, infilling of missing data values, etc.), mismatches between variability in observed and climate model based rainfall will continue to be considerable. Such a mismatch can have implications on the future projections by the climate models, and thus, the need to investigate if climate models sufficiently replicate variability in observed rainfall.

To understand variability of rainfall over the past, observational rainfall records can be used. However, to comprehend the physical mechanisms driving past and current climate variability and change, climate models are valuable tools (DDC 2015; Hoerling et al. 2006; Williams and Funk 2011). Furthermore, climate models provide physicallybased techniques of predicting future climatic conditions (Lu and Delworth 2005; Knutti and Sedláček 2012). Projections of future climatic conditions are vital for planning measures for adapting to the climate change impacts. 
However, evaluating present-day climate is essential to construe the realism of future changes (see, for instance, James et al. 2015). In other words, the reasonableness of the future climate change rainfall projections depends on how accurate the climate models reproduce observed or historical rainfall variability.

This study, therefore, aimed at investigating how well the climate models reproduce observed rainfall variability. To do so, a case study was conducted using rainfall observed across the Lake Victoria Basin (LVB). The LVB was selected because: (i) precipitation over it determines the level of the Lake Victoria which is the largest freshwater body in Africa and the second largest in the world, and (ii) it falls within one of the wettest parts of Africa. The study area was selected from Africa because of the recognition that has been given to the African climate as one of the "hot spots" in the earth climate system (Solomon et al. 2007; Kirtman and Pirani 2008). It was deemed necessary to take into perspective the issue of spatial resolution as well as the possible influence from the selection of a particular set of climate models. Eventually, three sets of climate models were used including CMIP3 (Meehl et al. 2007) i.e. phase 3 of the Coupled Model Inter-comparison Project (CMIP), phase 5 of the CMIP (CMIP5) (Taylor et al. 2012), and CORDEX RCM simulations.

Comparison between CMIP5 and CMIP3 gives an insight in the influence of the new versus older generation climate models. Comparison between CMIP and CORDEX shows the influence of the spatial resolution (dynamic downscaling) on the climate results. 


\section{Case Study Area and Data}

\subsection{Study Area}

The LVB (Figure 1) has a total catchment area of about $184,000 \mathrm{~km}^{2}$ stretching into five East African countries including Uganda, Kenya, Tanzania, Burundi and Rwanda. The basin comprises Lake Victoria which has a shoreline of $4,828 \mathrm{~km}$ and surface area of $68,800 \mathrm{~km}^{2}$. Lake Victoria is the largest freshwater body in Africa and the second largest in the world. Although, the climate of the LVB may be generally described to be tropical humid, it actually varies from Equatorial to semi-arid type (Anyah et al. 2006). Over Lake Victoria, rainfall tends to occur throughout the year. However, over the land mass of the LVB, there are intermittent droughts. Apart from the study area falling within the Great Lakes region, rainfall variation in the Equatorial region where LVB is located is greatly influenced by complex topography (with many mountains i.e. Mount Elgon, Mount Kenya, Mount Kilimanjaro, Mount Rwenzori, etc).

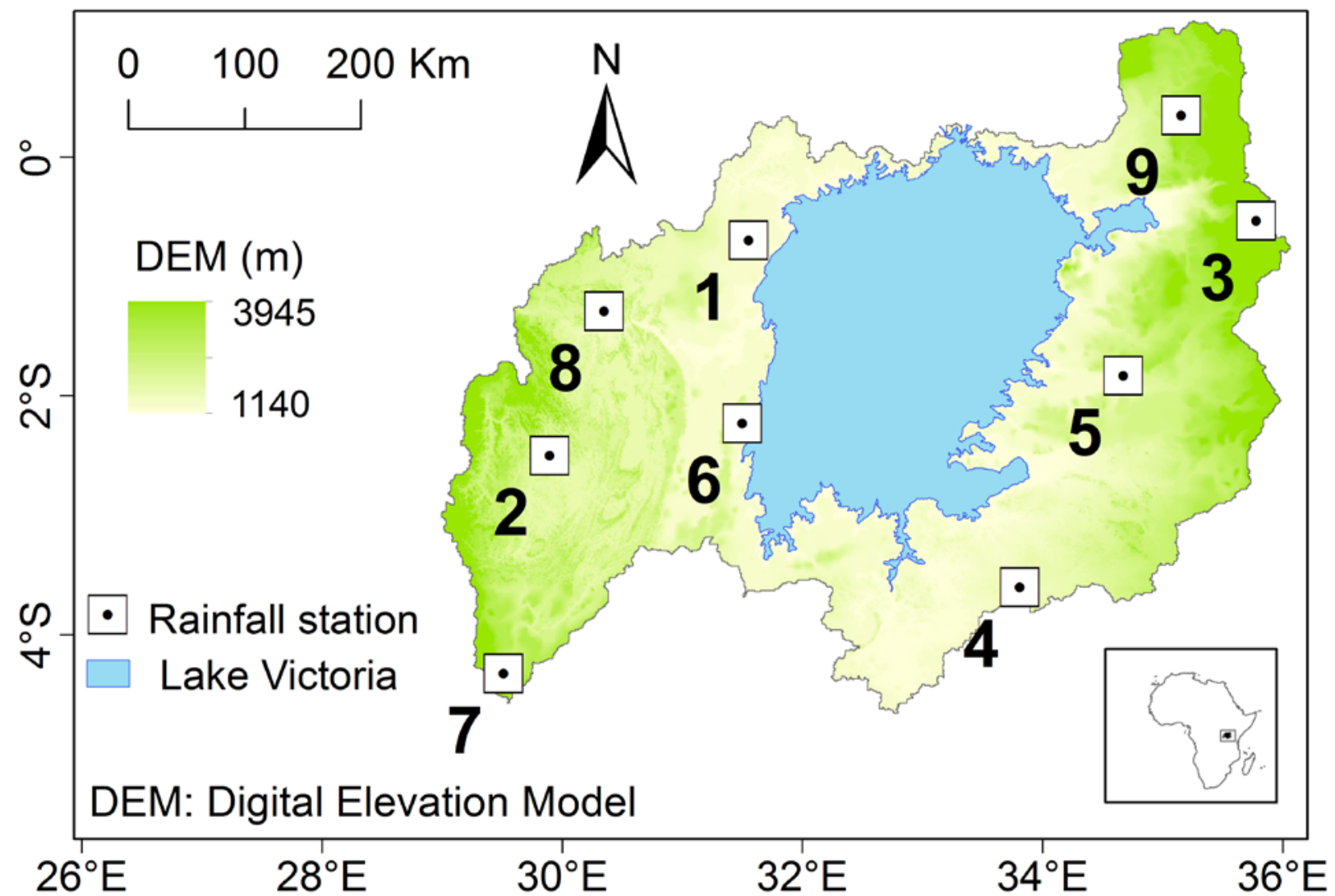

Figure 1 Lake Victoria basin and location of selected stations 


\subsection{Rainfall data}

Daily rainfall series from 1961 to 1990 observed at 9 locations across the LVB (Figure 1) were obtained from the database of the FRIEND/Nile (River Nile basin Flow Regimes from International, Experimental and Network Data) project. These rainfall series were adopted from a previous study Onyutha and Willems (2015) in which data quality control was performed. As seen from

Table 1, the maximum $\left(M_{a x}\right)$ historical daily rainfall intensity over the period 1961-1990 varied from about $80 \mathrm{~mm} /$ day (Station 3) to nearly $130 \mathrm{~mm} /$ day (Station 4). The coefficient of variation (CV) can be noted to vary from 1.4 (Station 2) to 2.7 (Station 8). This shows that there is a considerable variability on day to day basis in the LVB.

Table 1. Overview of selected stations

\begin{tabular}{cllllll}
\hline No. & Station ID & Station name & $\begin{array}{l}\text { Mean } \\
{[\mathrm{mm} / \mathrm{day}]}\end{array}$ & $\begin{array}{l}\text { CV } \\
{[-]}\end{array}$ & $\begin{array}{l}M_{a \mathrm{x}} \\
{[\mathrm{mm} / \mathrm{d}]}\end{array}$ & Country \\
\hline 1 & 9031026 & Kamenyamigo & 2.7 & 2.6 & 90.0 & Uganda \\
2 & 70009 & Kigali Aero Nyabarongo & 6.6 & 1.4 & 91.9 & Rwanda \\
3 & 9035002 & Londiani Forest & 3.2 & 2.2 & 79.7 & Kenya \\
4 & 9333005 & Maswa Hydromet & 2.5 & 3.1 & 129.5 & Tanzania \\
5 & 9134008 & Nyabassi & 3.9 & 2.3 & 120.0 & Tanzania \\
6 & 9131001 & Rubya Mission & 3.8 & 2.3 & 124.8 & Tanzania \\
7 & 10161 & Ruvyironza & 3.6 & 2.0 & 90.0 & Burundi \\
8 & 9030012 & Rwoho Forest & 2.6 & 2.7 & 120.6 & Uganda \\
9 & 8935076 & Turbo Forest & 3.6 & 2.2 & 82.5 & Kenya \\
\hline
\end{tabular}

Source: Onyutha and Willems (2015)

To further characterize rainfall, a particular day with its rainfall intensity less (greater) than $1 \mathrm{~mm} /$ day was considered dry (wet). Relevant information on wet and dry conditions in the study area was, as shown in Figure 2, given in terms 
of the long-term mean of: (i) monthly rainfall totals (Figure 2a), (ii) seasonal and annual rainfall totals (Figure 2b), (iii) the Maximum Wet Spell in each year (MWS, Figure 2c-d), (iv) the Maximum Dry Spell in each year (MDS, Figure 2e-f), (v) the total Number of Wet Days in each year (NWD, Figure 2g$\mathbf{h}$ ), and (vi) the total Number of Dry Days in each year (NDD, Figure 2i-j). The metrics MDS, NWD, NDD, and MWS were determined from rainfall of daily time scale.

As seen from Figure 2a-b, different seasons exist in the months of January-toFebruary (JF), March-to-May (MAM), July-to-September (JJAS), and Octoberto-December (OND). It is noticeable that rainfall is of a bi-modal pattern. The "long" rains occur in the MAM season (Figure 2a) and the main dry season is in JJAS. However, at Stations 3 and 9 as well as 5 to some extent, rains are somewhat received during the JJAS season. Rainfall conditions at Stations 3, 5 and 9 found in the North Eastern part of the LVB (compared with locations in other parts of the study area) are characterized by considerably large MWS and NWD (Figure 2c, g) as well as small MDS and NDD (Figure 2e, i). The smallest long-term annual rainfall, MWS, MDS, NWD, and NDD were obtained at Stations 4, 1, 5, 4, and 2, respectively. The corresponding largest values were obtained at Stations 5, 3, 4, 2, and 4, respectively. The slopes of the linear trends fitted to the dry and wet conditions at the various stations (Figure 2d, f, h, j) varied across the study area. Whereas MWS exhibited a decrease in the rainfall at some stations, negative trends were found at other locations. Similarly, both negative and positive trends were found across the study area in MDS, NWD, and NDD. In summary, Figure 2 clearly shows the spatiotemporal variability in rainfall across the LVB. Thus, it is vital to assess if the rainfall variability can be adequately reproduced by climate models. 


\section{KU LEUVEN}
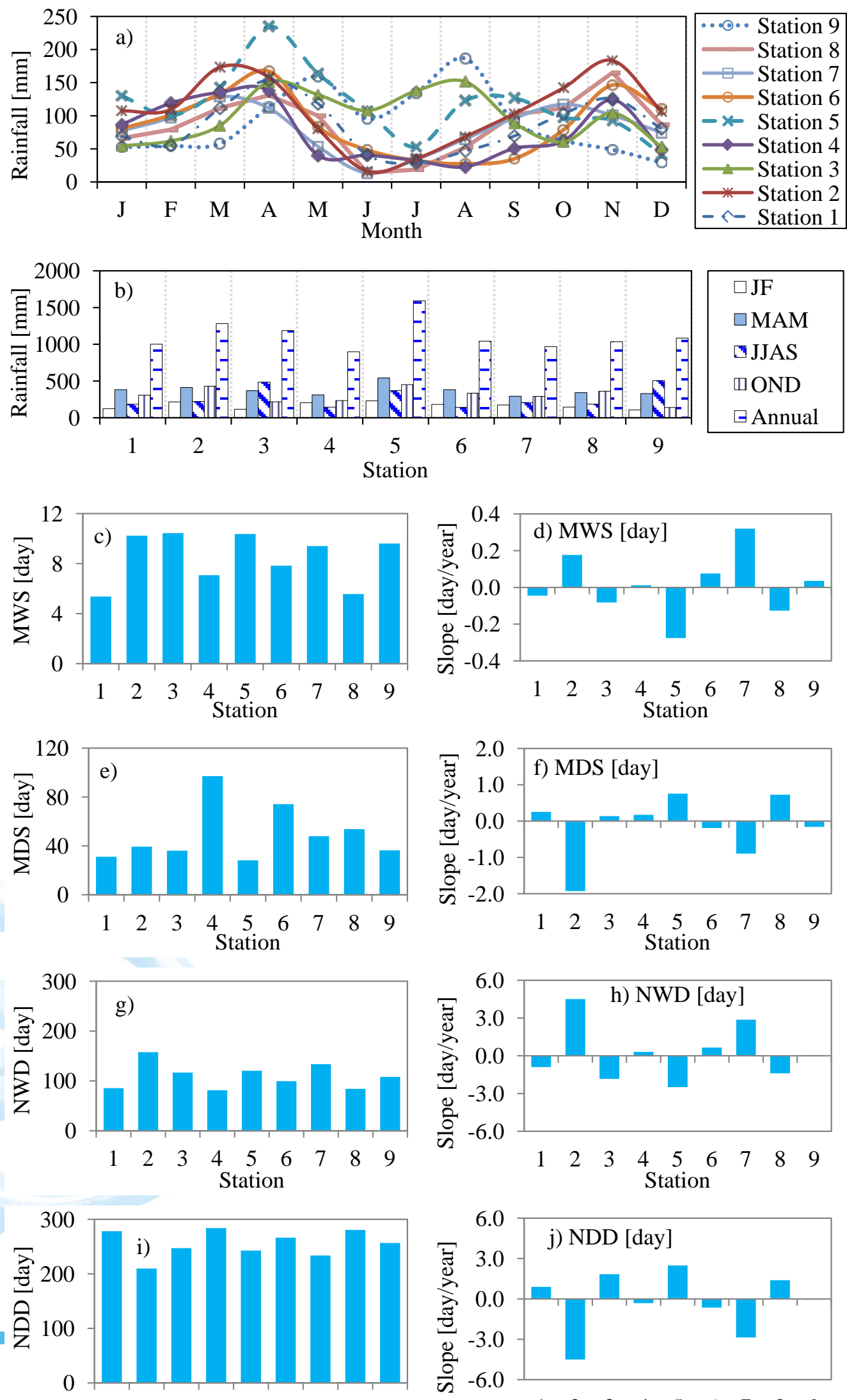
Figure 2 Rainfall totals for (a) monthly, and (b) seasonal and annual time scales as well as (c)-(j) information on wet and dry conditions in terms of long-term mean of (c) MWS, (d) MDS, (g) NWD, and (i) NDD, and (d, f, h, j) corresponding slopes of linear trends over the period 1961-1990.

\subsection{Climate Models}

The list of the three sets of climate model simulations used including CMIP3 and CMIP5 which respectively formed the basis of the fourth and fifth IPCC assessment reports, as well as CORDEX over the African domain can be seen from Table 2. For each set of simulations, a total of 14 climate models were considered.

From each GCM or RCM considered, daily data from the climate of the $20^{\text {th }}$ Century experiment (20C3M) over the period 1961-1990 were obtained. Furthermore, daily future projection series of the periods 2046-2065 (2050s) and 2081-2100 (2090s) were used for low (B1) and high (A2) greenhouse gas emission scenarios (CMIP3), and for low (RCP4.5) and high (RCP8.5)

Representative Concentration Pathways (RCPs) (CMIP5 and CORDEX Africa). The storylines from the selected IPCC special report emission scenarios of the CMIP3, with respect to the detailed socio-economic pathways, can be found in Nakicenovic et al. (2000). The RCPs are based on the global energy imbalances (radiative forcings) in watts per square meter by the year 2100 .

For the CMIP3, CMIP5 and CORDEX, if a climate model had several simulation runs, only the first run was considered for analyses. This was to eliminate bias due to the selection of model simulation runs. Some further details on the climate models can be found in Appendix A. The GCMs of the CMIP3 and CMIP5 simulations were selected for analyses following their use in previous studies (Onyutha et al. 2016; Nyeko-Ogiramoi et al. 2012b) for investigation of the impacts of climate change on the rainfall across the LVB.

Table 2. Selected climate models

\begin{tabular}{cccl}
\hline SNo & CMIP3 GCMs & CMIP5 GCMs & \multicolumn{1}{c}{ CORDEX RCMs } \\
\hline \multirow{2}{*}{1} & GISS-AOM & BCC-CSM1.1-M & CCLM4-8-17-MPI- \\
& & & ESM-LR \\
\multirow{2}{*}{2} & BCCR-BCM2.0 & BNU-ESM & CCLM4-8-17-CNRM- \\
& & & CM5 \\
\hline
\end{tabular}




\begin{tabular}{|c|c|c|c|}
\hline 3 & CGCM3.1(T47) & CANESM2 & CRCM5-MPI-ESM-LR \\
\hline 4 & CGCM3.1(T63) & CSIRO-MK3.6.0 & CRCM5-CanESM2 \\
\hline 5 & GFDL-CM2.0 & CNRM-CM5 & $\begin{array}{l}\text { HIRHAM5-NorESM1- } \\
\text { M }\end{array}$ \\
\hline 6 & GFDL-CM2.1 & FGOALS-G2 & $\begin{array}{l}\text { RACMO22T -EC- } \\
\text { EARTH }\end{array}$ \\
\hline 7 & INM-CM3.0 & GFDL_CM & $\begin{array}{l}\text { RACMO22T } \\
\text { HadGEM2-ES }\end{array}$ \\
\hline 8 & MPI- ECHAM4-OM & GFDL-ESM2G & RCA4-MIROC5 \\
\hline 9 & ECHAM5/MPI-OM & IPSL-CM5A-MR & RCA4-HadGEM2-ES \\
\hline 10 & ECHO-G & MIROC-ESM & RCA4-GFDL-ESM2M \\
\hline 11 & MIROC3.2(hires) & $\begin{array}{l}\text { MIROC-ESM- } \\
\text { CHEM }\end{array}$ & RCA4-CM5A-MR \\
\hline 12 & MIROC3.2(medres) & MPI-ESM-LR & RCA4-CSIRO-Mk3-6-0 \\
\hline 13 & CSIRO-MK3.0 & MPI-ESM-MR & REMO2009-CM5A-LR \\
\hline 14 & CSIRO-MK3.5a & MRI-CGCM3 & $\begin{array}{l}\text { REMO2009-MPI-ESM- } \\
\text { LR }\end{array}$ \\
\hline
\end{tabular}

\section{Methodology}

To investigate how well the climate models reproduce observed rainfall variability, a number of metrics were used. To select each metric, the fact that variability analyses depend on the relevant time scale was taken into perspective. For instance, to analyze decadal anomalies in rainfall, 10-year time scale can be selected. To investigate the co-occurrences (or association) of events in observed and climate model based series, the metrics correlation and coefficient of variation were used. Assessment was also made to find whether the climate models replicate the measure of long-range dependence from 
observed rainfall. Variability of rainfall greatly influences the potential climate change impacts. In this study, changes in the MDS, and MWS were considered because variation in wet and dry spells is important for planning risk-based water resources applications.

\subsection{Coefficient of variation}

Coefficient of variation (CV) (which is the ratio of the standard deviation to the mean) was computed for the rainfall of daily and annual time scales. Values of the CV were also obtained for the MDS, and MWS. The values of CV computed using observed rainfall and those based on series obtained from climate models (considering CMIP3, CMIP5, and CORDEX simulations) were compared.

\subsection{Co-variation of observed rainfall and historical data form climate models}

The measure of how closely the historical re-analyses rainfall from the climate models resonate with the observed data was computed in terms of Pearson correlation. This was done for daily and annual time scales. Like for the CVs, the coefficients of correlation between observed and climate model based series were also computed using the metrics MDS, and MWS considering CMIP3, CMIP5, and CORDEX simulations.

\subsection{Measure of long-range dependence}

Some classical statistical metrics CV, mean, correlation, etc. assume that the sample comprises independent, and identically distributed variables. However, this assumption tends to be violated in reality based on the nature of hydroclimatic variables which are characterized by persistence. Observations far away in time tend to rely on one another, and this feature can be considered as the Long-Range Dependence (LRD), a metric which is very crucial in characterizing the variation in a given data. The LRD can be measured in terms of the Hurst exponent $H$ (Hurst 1951). A typical white noise exhibits $H=0.5$. In reality, values of $H$ tends to be greater than 0.5 and thus, associated with large-scale and/or multiple-scale variability in the series. In other words, $H>$ 0.5 indicates that successive values in the series depend on previous values. For instance, if a value is greater than the mean value, the next value is supposed to be greater than the sample mean with a probability greater than 0.5 . Therefore, 
$H$ is a measure of persistence. The stronger the persistence, the larger the value of $H$. The computation of $H$ was based on the framework proposed by Koutsoyiannis (2003a; 2003b). The Hurst exponent $H$ computed using observed daily rainfall and those based on series obtained from climate models (considering CMIP3, CMIP5, and CORDEX simulations) were compared.

\subsection{Changes in rainfall}

To assess the impact of climate change, the historical rainfall and those projected by the climate model runs were compared. The changes in rainfall were obtained in terms of the ratio of the difference between the future and observed rainfall CV to the observed rainfall CV. This was done based on the CMIP3, CMIP5, and CORDEX simulations.

\section{Results}

\subsection{Variation in wet and dry conditions}

Figure 3 shows correlation coefficients and values of CV for rainfall over the climate baseline (1961-1991). The minimum difference between the ensemble mean of the $\mathrm{CV}$ values from the climate models and the $\mathrm{CV}$ of the observed rainfall was obtained at Station 5 (for CMIP3, Figure 3a), Station 7 (for CMIP5, Figure 3c), and Station 8 (for CORDEX, Figure 3e). At Station 2, most climate models (CMIP3, CMIP5, and CORDEX) under-estimated the variability in MDS of observed rainfall. The ranges of the CV values were narrower for CORDEX (Figure 3e) than those of the CMIP3 and CMIP5 (Figure 3a, c). Furthermore, for each set of climate model simulations (CMIP3, CMIP5, and CORDEX), the range of the CV values varied from one station to another (Figure 3a, c, e). This indicates the differences among the climate models in capturing the rainfall variability across the study area. The correlation between MDS of observed rainfall (considering all the stations) and the series 
from climate models were mainly between -0.45 and 0.45 (Figure $3 \mathbf{b}, \mathbf{d}, \mathbf{f}$ ). The ensemble mean of the correlation coefficients was low (close to zero) for all the sets of climate models. This means that, by considering the averaged results of the climate models, dry spell conditions across the study area are poorly reproduced by the CMIP3, CMIP5, and CORDEX simulations.
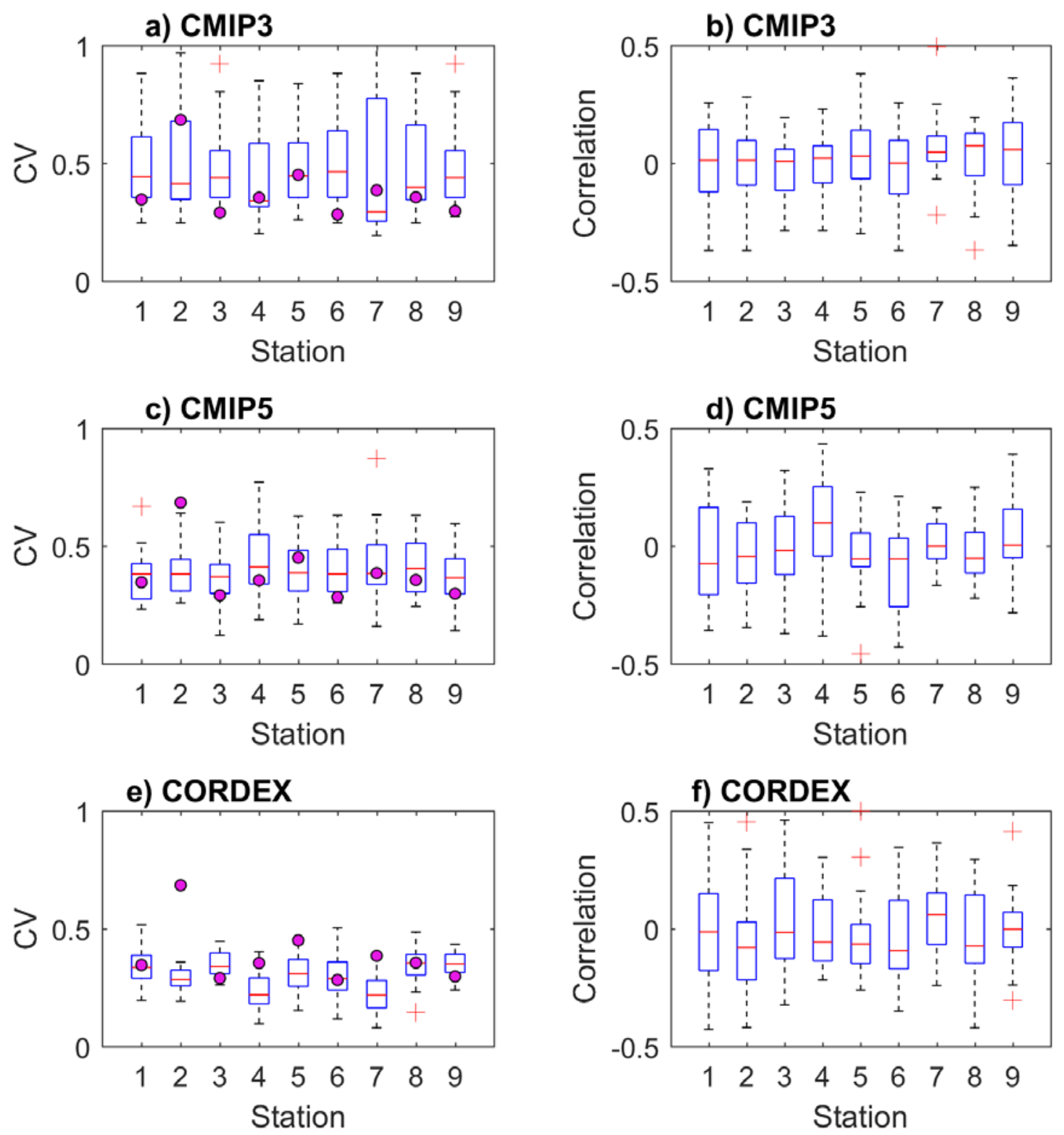

Figure 3 Comparison of MDS from observed rainfall and series obtained from climate models of (a)-(b) CMIP3, (b)-(c) CMIP5, and (e)-(f) CORDEX. The filled-in markers in charts (a), (c) and (e) denote the CV values obtained using observed rainfall.

Figure 4 shows results for the co-variation of the MWS obtained from observed rainfall series extracted from the climate models over the climate baseline (1961-1991). At each selected station, the CV of the MWS of observed rainfall is over-estimated by the GCMs of the CMIP5 simulations (Figure 4c). 
Generally, the range of the CVs is lower for the CORDEX RCMs than those from the GCMs of the CMIP3 and CMIP5 simulations (Figure 4a, c, e). The range of the coefficients of the correlation between the MWS from observed series and that of the observed rainfall (considering all the stations) varies from -0.42 to 0.41 (CMIP3, Figure $4 \mathbf{b}$ ), -0.5 to 0.51 (CMIP5, Figure 4d), and -0.51 to 0.58 (CORDEX, Figure 4f). Like for the dry spell as shortly seen before, the ensemble mean of the correlation coefficients is low (close to zero) for all the sets of climate models. This, again, means that the capability of the climate models (when considered in an averagely combined way) in capturing the variability of wet spell across the study area is low. 

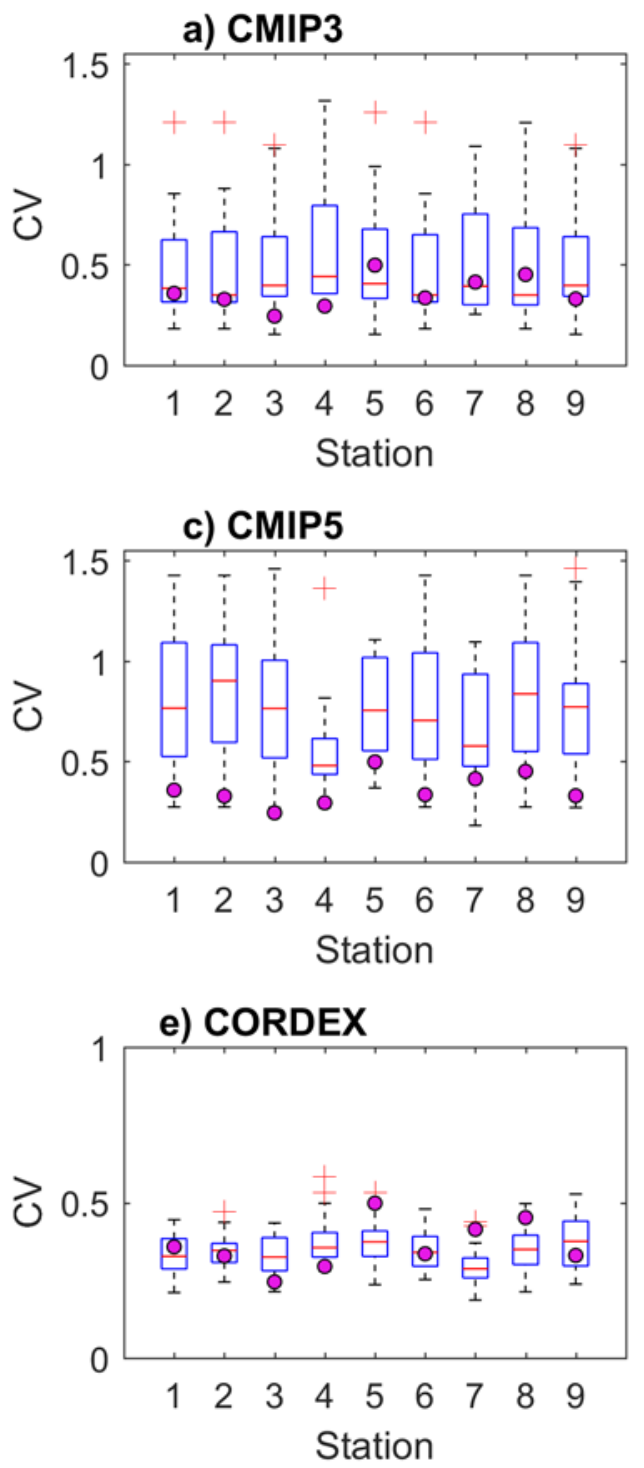

b) CMIP3

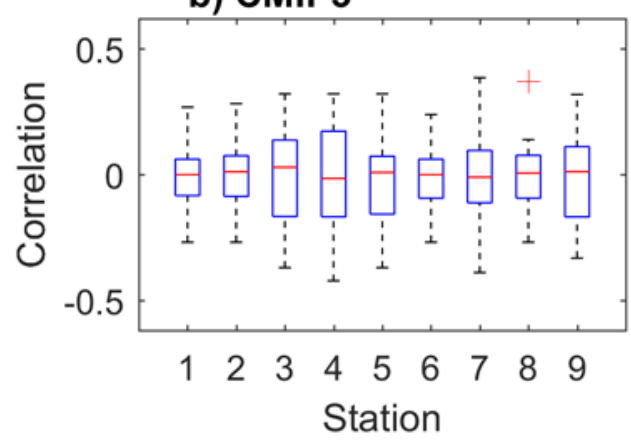

d) CMIP5
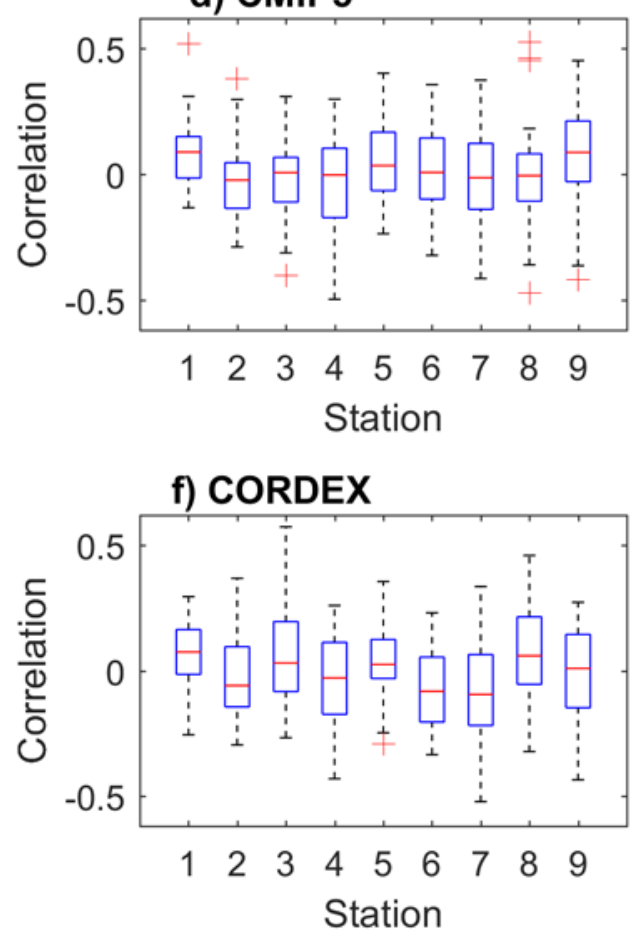

Figure 4 Comparison of MWS from observed rainfall and series obtained from climate models of (a)-(b) CMIP3, (b)-(c) CMIP5, and (e)-(f) CORDEX. The filled-in markers in charts (a), (c) and (e) denote the CVs obtained using observed rainfall.

\subsection{Variation in daily rainfall}

Figure 5 shows an assessment of the Hurst phenomenon using daily rainfall series. The smallest (highest) value of the Hurst exponent $H$ in the observed rainfall was obtained at Station 1 (Station 3). These values of $H$ are greater than 0.5 (which is known to characterize white noise). The GCMs of the CMIP3 (Figure 5a) tended to generally over-estimate the values of $H$ from observed daily rainfall. The best performance of the CMIP3 models was at Station 3 (Figure 5a). The CMIP5 models, on average, performed fairly well at Stations 2, 4, and 9 (Figure 5b). The best performance for the CORDEX was at Stations 2-3, 6-7, and 9 (Figure 5c). The performance of the climate models in 
reproducing the multiple-scale variability in daily rainfall was, on average, best for the CORDEX RCMs (Figure 5c) followed by CMIP5 GCMs (Figure 5b) and lastly the CMIP3 GCMs (Figure 5a). This suggests that the ability of the climate models to reproduce the large-scale random fluctuations in the series increases with the spatial resolution of the model outputs. It is noticeable that the values of $H$ from observed rainfall are mainly below the ensemble mean obtained from the GCMs (especially of the CMIP3) models. In other words, the outputs of the climate models are more persistent than the observed series. This high persistence in the model outputs indicates that the present value can depend on that obtained several years ago. In response to the persistently increasing greenhouse gas concentrations with which the models are forced, the long-term rainfall series from the climate models tend to be characterized by monotonic trends (deterministic function of time). 


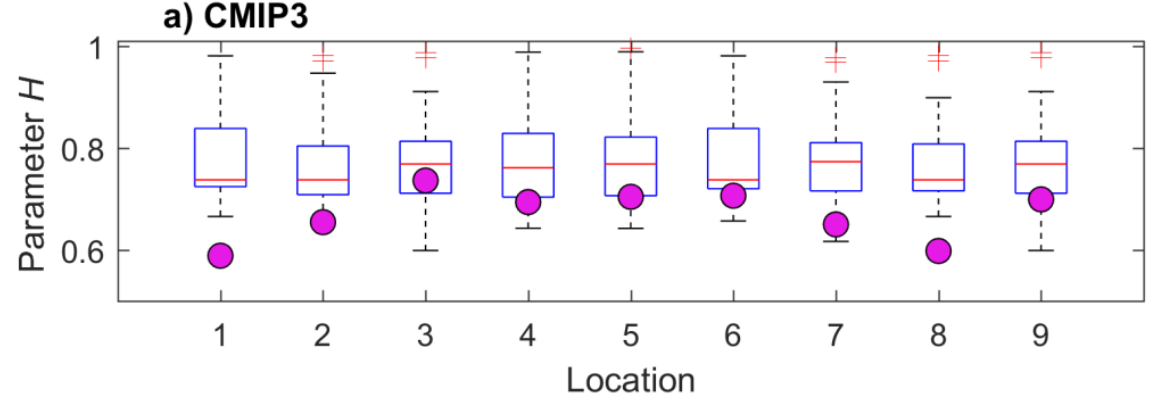

b) CMIP5

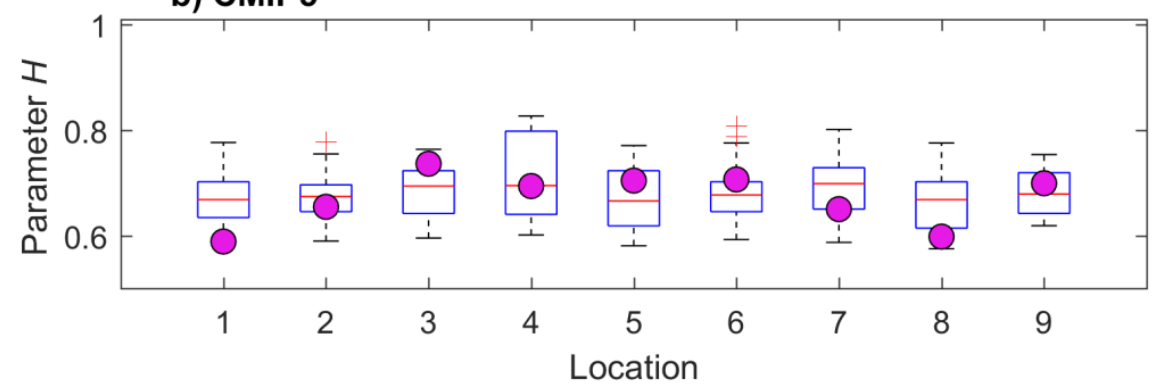

c) CORDEX

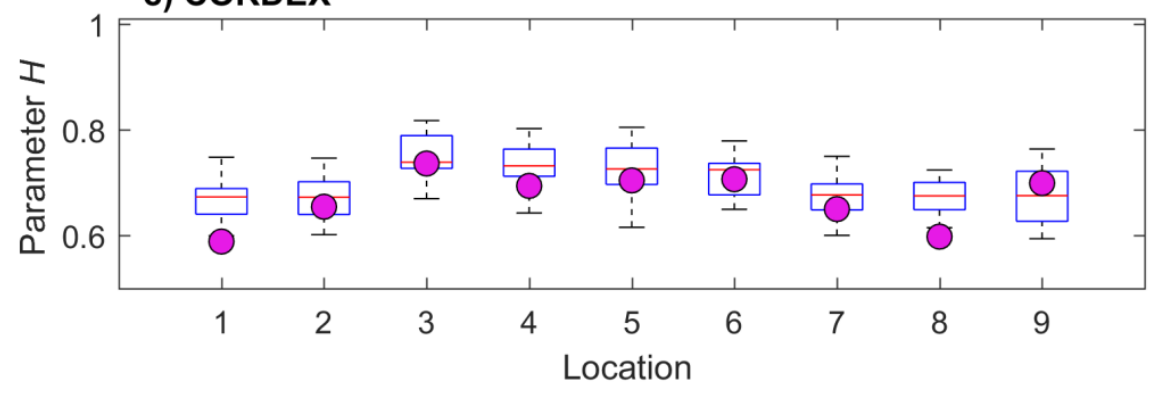

Figure 5 Comparison of Hurst parameter $(H)$ from observed and climate model based daily rainfall of (a) CMIP3, (b) CMIP5, and (c) CORDEX. The filled-in markers in each chart denote the values of $H$ from observed rainfall.

Figure 6 shows results of analyses of the co-variation of the observed and climate model based rainfall of daily time scale. It is noticeable that the variability in observed rainfall is generally under-estimated by the CMIP3 GCMs (Figure 6a) compared with the results from the CMIP5 GCMs and the CORDEX RCM simulations (Figure 6c, e). The largest range of CV is obtained for CMIP5, followed by CORDEX and lastly CMIP3. Due to high variability in daily rainfall, the ensemble mean of coefficients of correlation are low for all the three sets of climate models (Figure $\mathbf{6 b}, \mathbf{d}, \mathbf{f}$ ). This indicates, on average, reduced capacity for climate models to correctly capture the time of occurrences and the magnitude of daily rainfall events (when considered in a combined way) which are of direct relevance for planning of risk-based water resources applications. 


\section{KU LEUVEN}
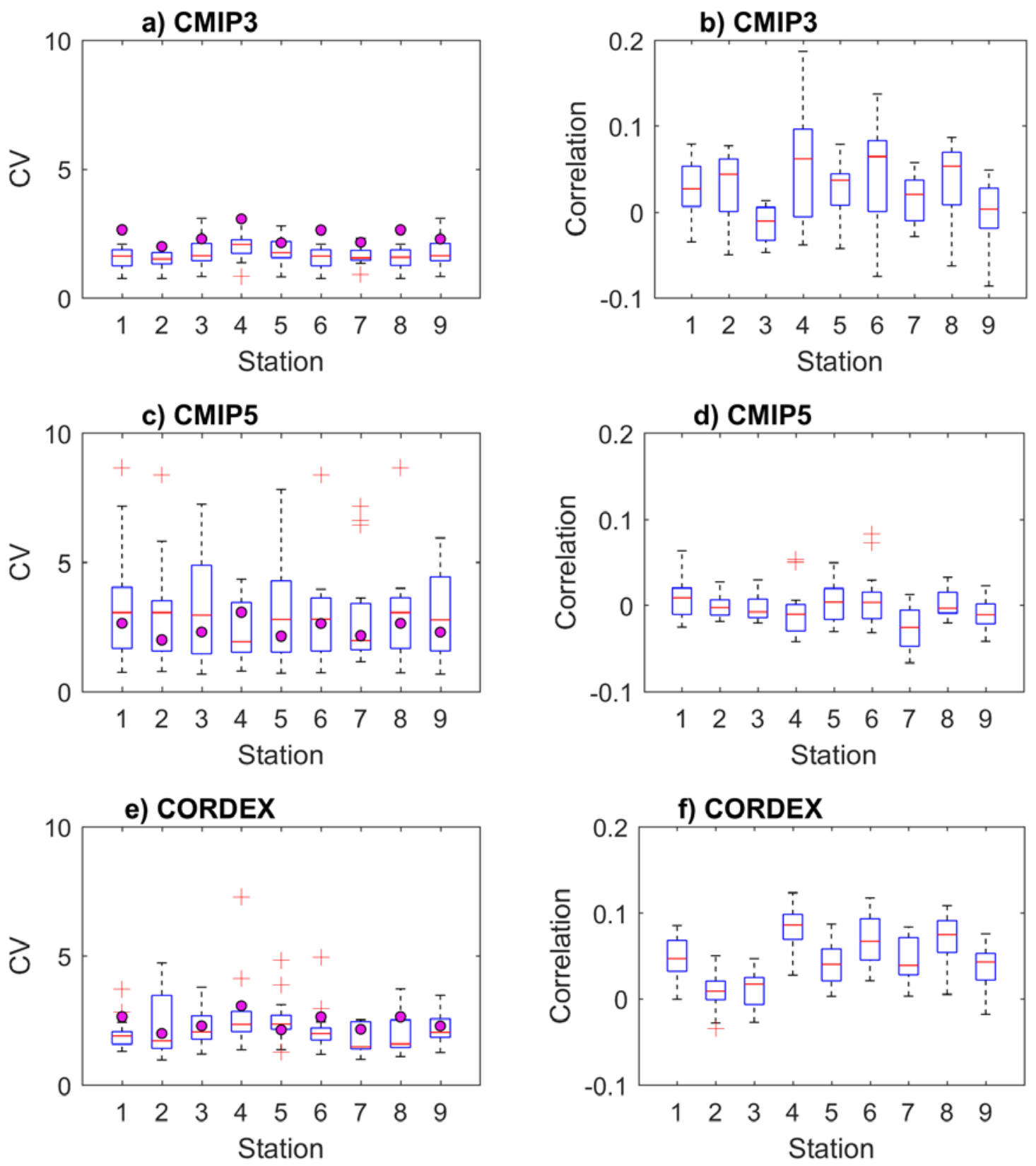

Figure 6 Comparison of observed and climate model based daily rainfall of (a)-(b) CMIP3, (b)-(c) CMIP5, and (e)-(f) CORDEX. The filled-in markers in charts (a), (c) and (e) denote the CV values from observed rainfall. 


\subsection{Variation in annual rainfall}

Figure 7 shows the assessment of how well the climate models reproduced the annual rainfall. The CV in observed rainfall was generally over-estimated by the CMIP3 and CMIP5 (Figure 7a, c) compared with the results from the CORDEX (Figure 7e). Like for the MDS and MWS (as already seen in Figure 3 and Figure 4), the ensemble mean of the correlation coefficients (Figure $\mathbf{7 b}, \mathbf{d}, \mathbf{f}$ ) for all the three climate models were close to zero. This, again, shows the reduced capacity of the climate models, on average, to accurately reproduce variability in observed rainfall across the study area.

a) CMIP3

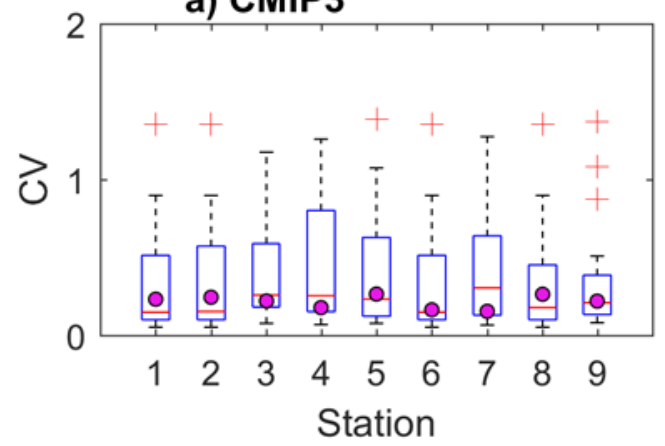

c) CMIP5

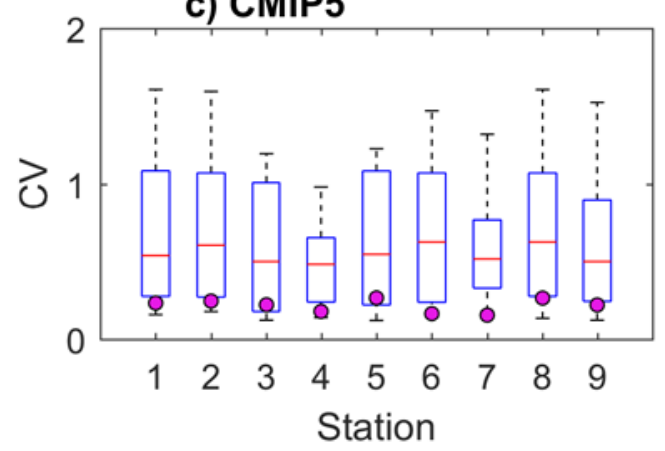

e) CORDEX

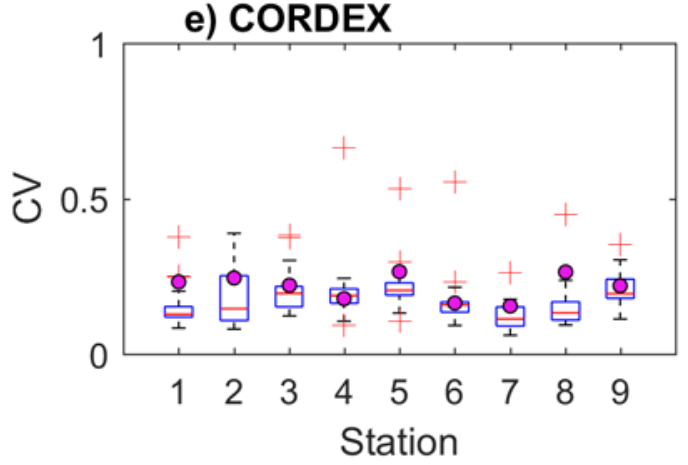

b) CMIP3

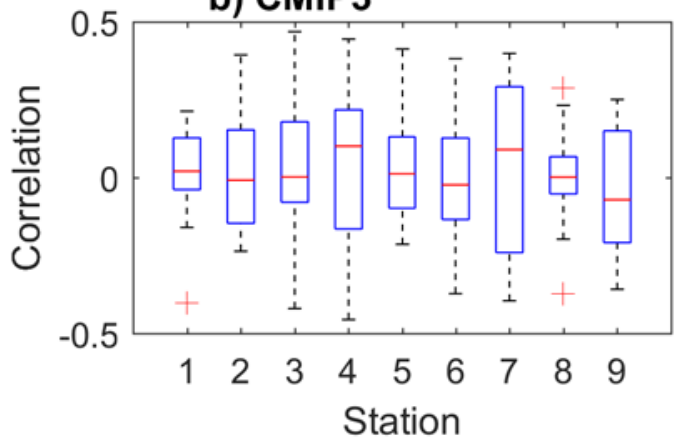

d) CMIP5
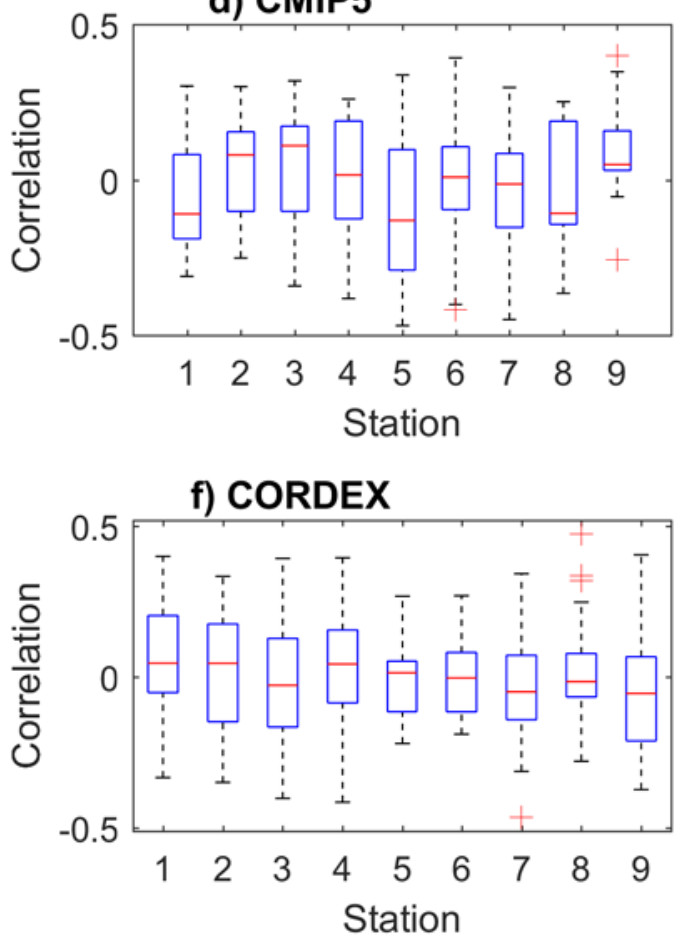

Figure 7 Comparison of observed and climate model based annual rainfall. The filled-in markers in charts a), c) and e) denote the CV values from observed rainfall. 


\subsection{Changes in rainfall}

Figure 8 shows the amount by which, on average, the CV of future annual rainfall will change compared with that of the 1961-1990 period. The largest changes in the variability of annual rainfall were found in the CMIP5 models. At most of the selected meteorological stations, the CMIP3 and CMIP5 projected an increase of variability in annual rainfall. However, based on the CORDEX simulations, CV in the future annual rainfall of the 2050s and 2090s will be negative (positive) at meteorological stations 1-2, 5, and 7-8 (3-4, and 6). At each station, the projections of the $\mathrm{CV}$ in annual rainfall based on CMIP3, CMIP5 and CORDEX simulations were different. This is indicative of the influence of the selection of the set of climate models for investigation of climate change impacts. Though not shown in Figure 8 (for brevity), changes in the CV of daily rainfall, MDS and MWS can be seen in Appendix B. According to CORDEX RCMs, the variability in the future MDS at Stations 12, 4-5, and 7-8 will be lower than that of the 1961-1990 period. The CMIP3 simulations also showed less MDS variability under future than past climatic conditions at Stations 2, 4, and 6-7 (Appendix B1). However, based on the CMIP GCMs, the MDS variability will be higher (lower) in the 2090s and 2050s than that of the climate baseline (1961-1990). The CMIP5 GCMs generally show that the CV of the future MWS will be higher than that of the observed MWS at all the selected stations. At Stations 1-2, 5 and 7 (3-4, 6 and 9), the CMIP3 projections showed that there will be a decrease (an increase) in the CV of MWS in the 2050s and 2090s compared to that of the 1961-1990 period (Appendix B2). According to the CORDEX simulations, a decrease (an increase) in the CV of the MWS will be exhibited at Stations 5, 7-8 (1-4, and 6). Ensemble mean of the CV in daily rainfall under future climatic conditions based on the CMIP3 and CMIP5 simulations was found to be higher than those of the observed or past (1961-1990) period (Appendix B3). On the contrary, 
the CORDEX simulations, indicated that the CV of daily rainfall at most locations will be less for the future than that of the past climatic condition. In summary, the ensemble amount by which the variability in the MDS and MWS will change under future (compared with the past) climatic conditions was found to vary from one set of climate models to another (see Appendix B). Even for the past climatic conditions, the differences in how the variability in observed rainfall in terms of dry and wet spells could be reproduced was already noted to vary from one set of climate models to another (see Figure 3 and Figure 4).
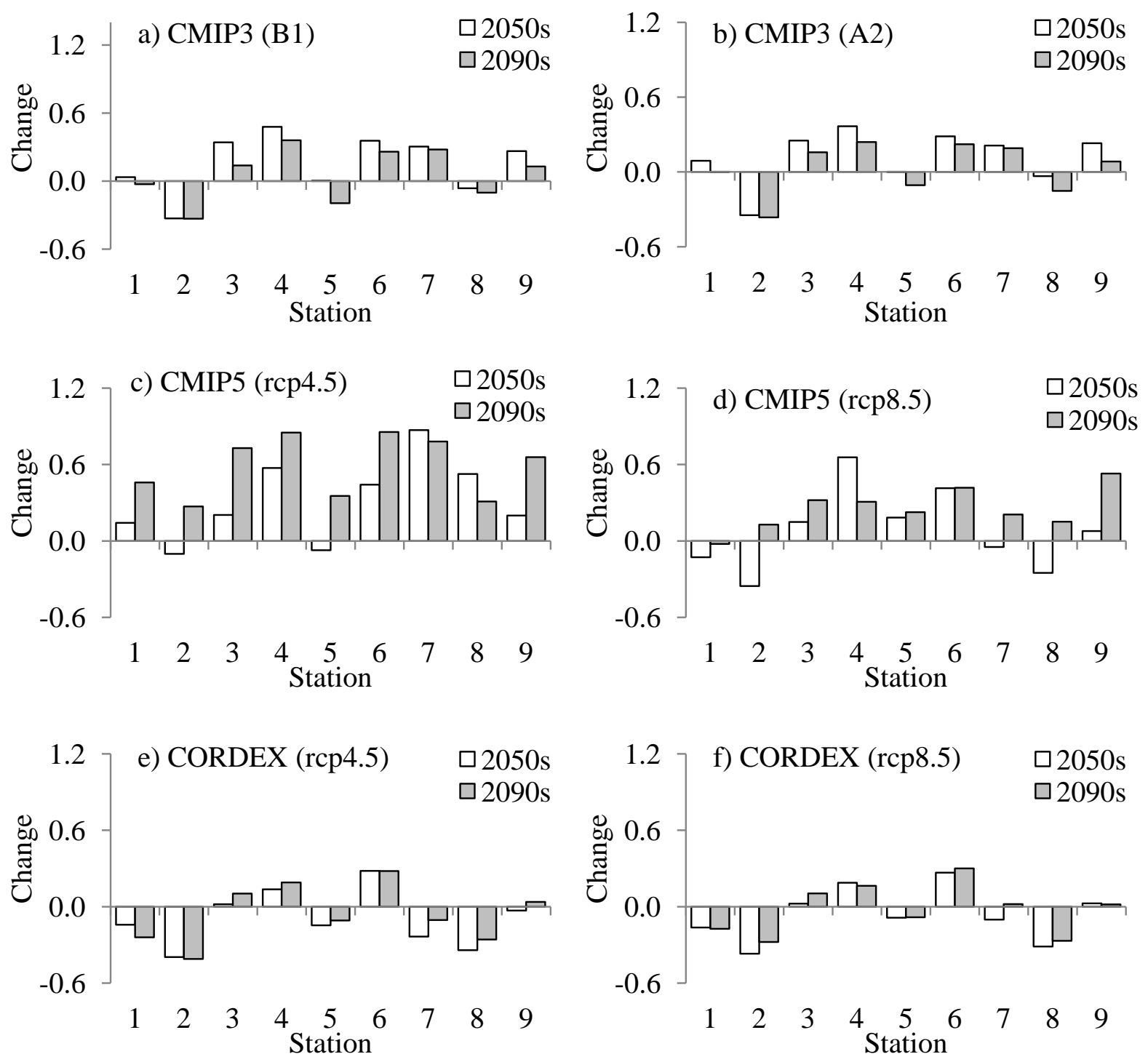
Figure 8 Ensemble mean changes in the CV of annual rainfall for (a-b) CMIP3, (c-d) CMIP5, and (e-f) CORDEX RCM simulations over the periods 2050s and 2090s

\section{Discussion}

\subsection{Variation in wet and dry conditions}

The reduced capacity of the climate models to accurately capture the variability in both wet and dry conditions across the study area could be due to their limitation in accurately representing the complexity of various factors which might synergistically influence the variation in rainfall of the Equatorial region. As seen from the Introduction Section, some of the key factors that need to be adequately reproduced by climate models regarding the driving forces of rainfall variability across the study area include: the large-scale oceanatmosphere interactions, the latitudinal migration of ITCZ, influences from regional topographical features such as water bodies (e.g. Lake Victoria, Lake Kyoga, Lake Albert, Lake Turkana), and high mountains (such as Mount Elgon, Mount Rwenzori, and Mount Kenya). How each factor influences rainfall should be considered with respect to natural variability in both dry and wet conditions. For instance, with respect to the Walker circulation, the increased (reduced) convection in the positive (negative) phase of the Indian Ocean dipole is known to engender wet (dry) conditions in the equatorial region where the study area is located.

Currently, the GCMs have horizontal resolutions of between 250 and $600 \mathrm{~km}$ (DDC 2015). The main problem with the GCMs are that they have coarse spatial resolution, lack proper modelling of some physical processes such as those related to clouds at smaller scales, simulation of different responses due to various feedback mechanisms, for instance water vapor and warming, clouds and radiation, ocean circulation and/or ice and snow albedo (Onyutha et al. 
2016). With respect to spatial resolution, the coarse scale makes the GCMs to represent the orography in a smoothened way thereby reducing the capability to depict the influence of topographical features on rainfall variability across regions. Thus, the need for refined spatial resolutions of the climate models. For the CORDEX climate models, the spatial resolution of the RCMs are greatly refined (such as grid-spacing of $0.44^{\circ}$ ) for a more considered representation of the regional climate than the GCMs. However, even in the CORDEX simulations, significant biases in individual models depend on the selected subregion and season (Akinsanola et al. 2015). These biases could be due to various reasons. For instance, the bias in the CORDEX RCM based precipitation over West Africa was recently ascribed to the strong cyclonic circulation observed at $850 \mathrm{mb}$ pressure level (Akinsanola et al. 2015). Generally, for the CORDEX results over the continent of Africa, many sources of uncertainty need to be identified and quantified for an improved robustness in generating climate change signals (Dosio and Panitz 2016) as well as reproducing natural variability of observed climatological variables.

Despite the need to improve the climate models, it is vital to note that quality long-term observed series are required. In many areas of Africa especially the sub-Saharan region where the study area is located, weather stations are of poor or uneven distribution and low density. Historical development, political turmoil, and lack of maintenance of data observation equipment interrupt the operationality of several weather stations (Onyutha 2018a). Eventually, the number of operational weather stations tend to vary in both space and time. Although cases of missing data records tend to be tackled through in-filling and spatial interpolation based on data from other stations, such variation of weather stations in space and time can bring about exaggerated rainfall variability (Onyutha 2018a) and bias in trends (Maidment et al. 2015; Washington et al. 2013). For data scarce regions, uncertainties from a number of sources such as model input series (due to observation errors, data limitation, in-filling of missing data values, etc), and the incompatibility of the model structure with data availability, altogether lower the accuracy and reliability of model predictions (Onyutha and Willems 2018). One might think that data scarce regions (like the study area) have a number of Freely Available Rainfall Products (FARPs) to circumvent challenges of observed data limitation. Examples of such FARPs include the 'Centennial Trends' rainfall dataset (Funk 
et al. 2015), Climatic Research Unit Time-Series (Harris et al. 2014), African Rainfall Climatology (Novella and Thiaw 2013), Princeton Global Forcings (Sheffield et al. 2006), Global Precipitation Climatology Project (Adler et al. 2003), Tropical Rainfall Measuring Mission (Huffman et al. 2007), etc. However, long-term FARPs tend to be coarse (monthly or annual), and those that have high (daily or hourly) temporal resolution are over short periods. Furthermore, for these FARPs there is always the concern of their consistency and accuracy in capturing high-resolution extreme events (such as of temperature and rainfall in both space and time) which are of paramount importance regarding the climate change impacts. Besides, for predictive adaptation regarding the impacts of climate variability and change, long-term and high-resolution weather data are required for reliable non-stationary assessment of extreme events over epochs characterizing cold/hot and wet/dry conditions (Onyutha 2017). Therefore, if long-term and high quality observed weather conditions in terms of meteorological series such as rainfall, temperature, evaporation, etc are available, they would support reliable calibration of climate models prior to predictions of future climatic conditions. It is imperative that the government or policy makers in data scarce regions (for instance where the study area is located) generously invest in collection of weather data at high spatial and temporal scales, and clear policies on data sharing to permit access by researchers in support of scientific research should be adopted (Onyutha 2018b).

\subsection{Multi-scale variability}

Due to the refinement in the spatial scale, it is interesting that the climate models seem to improve on their capacity to replicate the multi-scale variability in rainfall (as demonstrated for the study area). Although, in this study, statistical LRD was assessed in terms of the Hurst parameter, it was remarked by Kerkhoven and Gan (2011) that the Hurst exponent approach (as well as that 
based on autocorrelation) can fail in the presence of systematic trends (such as seasonal cycles, regulation, or climatic change). To simulate effects of anthropogenic emissions, an increasing concentration of greenhouse gases is the only persistent temporal forcing (MacKellar et al. 2014). Eventually, long-term outputs (such as rainfall and temperature) from climate models tend to be characterized by monotonic trends. Hurst exponent computed from series with monotonic trends tend to be affected (something which might have been the case for this study though not examined). Furthermore, when uncorrelated data are superimposed on a long-term trend, they will exhibit autocorrelation (Bhatthacharya et al.1983). To determine an underlying multifractal behavior of time series in the presence of long-term trends, Kantelhardt et al. (2002) developed multifractal detrended fluctuation analysis (MFDFA). Though not applied in this study (for brevity), the multifractal properties of observed and climate model based rainfall can be assessed using MFDFA.

Changes in rainfall will occur under future climatic conditions due to their persistence. Thus, for reliable assessment of long-term rainfall changes, natural variation in rainfall should adequately be characterized in terms of the statistical dependence. This means, climate models can still further be improved with respect to natural variability of rainfall at local scales. However, for this improvement, whether concepts of statistical dependence (such as fractality, spatio-temporal scaling behavior or self-similarity) of variables such as rainfall can explicitly contribute in that respect is a crucial consideration. For instance, if persistence in observed rainfall is to be sufficiently depicted, the rising and falling trends in the past climatology should adequately be captured by the climate models. One example of a framework through which the Hurst phenomenon can be considered is the Markovian framework. In this approach, only the latest observations influence the future probabilities. In another way, the Hurst-Kolomogorov HK (Kolmogorov 1940; Hurst 1951) framework can be utilized. Here, the entire record of the part realizations is taken into account to condition the simulations of future climatic conditions (Koutsoyiannis 2011). Important note that can be taken is that, consideration of the HK framework would lead to larger estimates of uncertainty for the future climate than in the case when the predicting models do not take the HK into account.

The rationale for adequately reproducing the statistical dependence in rainfall is two-fold. Firstly, the natural variation in rainfall over most parts of the world is 
so significant that it can conceal climate change signal (Sun et al. 2018).

Secondly, statistical dependence properties (such as scaling behavior) of rainfall can be transmitted to river flow through rainfall-runoff generation process. This was why, for instance, Tessier et al. (1996) found the power spectra of both rainfall and runoff time series were characterized by two distinct features something which these authors associated with the time scale of atmospheric structures of planetary extent (that is, the synoptic scale). An unconditional sample uncertainty associated with the natural variability (within even a perfectly stable climate) comprises a significant source of uncertainty in predicting the response of a catchment to future climate change (Kerkhoven and Gan 2011). For instance, Kerkhoven and Gan (2011) showed (for river flows of Athabasca River Basin and Fraser River Basin of Canada) that uncertainties associated with multifractal variation in flow (which apparently depends on rainfall) were huge, on the order of $\pm 50 \%$, and comparable with the level of uncertainty due to GCM selection.

\section{Conclusions}

This paper assessed the performance of three sets of climate models (CMIP3, CMIP5 and CORDEX simulations) in reproducing variability in observed rainfall. A case study was conducted using data from the Lake Victoria Basin in Africa. From the daily rainfall, the Maximum Dry Spell (MDS) and Maximum Wet Spell (MWS) in each year were extracted. For both observed and climate model based rainfall, coefficients of variation in the MDS and MWS were computed. How well the climate models reproduced the MDS and MWS in 
observed rainfall was assessed in terms of correlation. The measures of longrange dependence obtained from observed and climate model based daily rainfall were compared. From this study, the following conclusions were made:

1) For the selected period 1961-1990, the CORDEX RCMs reproduce variability in daily rainfall (across the case study area), to some extent, better than the CMIP3 and CMIP5 GCMs. This was because of the spatial resolutions of the CORDEX RCMs which were higher than those of the CMIP3 and CMIP5 GCMs. However, on average, both GCMs and RCMs exhibited reduced capacity to adequately capture the time of occurrences and the magnitudes of observed daily rainfall events (when considered in a combined way).

2) How well the variability in observed wet and dry conditions could be reproduced depends on the specific GCM (for CMIP3 or CMIP5) or RCM (for the CORDEX). Whereas some models performed well, others were poor in reproducing observed wet and dry conditions.

Furthermore, the ensemble amount by which the variability in the wet and dry conditions will change under future (compared with the past) climatic conditions was found to vary from one set of climate models to another (and even among the GCMs or RCMs). Thus, differences in rainfall variability among the various sets of climate models (as well as among the GCMs or RCMs) should be considered in climate change impact investigations. Realizing that the reasonableness of the future rainfall projections depends on how well the climate models reproduce variability in observed rainfall, the finding from this study suggests that analyses can be done on a case by case basis. In other words, to minimize bias in the future rainfall projections, GCMs or RCMs which 
adequately reproduce variability in wet and dry conditions from observed rainfall can be considered for further statistical analysis of the changes especially on the basis of statistical methods for downscaling.

3) For reliable assessment of long-term rainfall changes, natural variation in rainfall should adequately be characterized in terms of the statistical dependence. Room for further improvement of the climate models (with respect to natural variability of rainfall at local scales) still exists.

However, for this improvement, whether concepts of fractality, spatiotemporal scaling behavior or self-similarity (of variables such as rainfall) can explicitly contribute in that respect is a crucial consideration.

Furthermore, as opposed to the common practice of evaluating performance of climate models by comparing their outputs with the observed series over the well-known climate baseline (1960-1990), it is recommended that the splitsample technique (Klemeš 1986), a long tradition of model build up and performance evaluation (in which there are both calibration and validation processes), be adopted for GCMs or RCMs. Calibration can be done based on a period of, say, 30 years, and for the next 30-year period, validation is performed. In other words, the data for validation is separate from that used in calibration. Reasonableness of future projections would be based on how well a 
climate model reproduces natural variability over both calibration and validation periods.

Finally, whereas the ensemble measure of how variability in observed rainfall could be replicated was shown to be low for the various sets of climate models, it is not intended that the overall message from this paper be taken in a negative way. The results from this study are rather to underscore the significance of adequately characterizing natural variability in observed climatology to boost confidence on the predictions from climate models regarding future climatic conditions.

\section{Acknowledgments}

The research was financially supported by an IRO PhD scholarship of KU Leuven. This paper is dedicated to the late Dr. Eng. Paul Nyeko-Ogiramoi who passed on untimely in June 2016 while he was a Principal Engineer in the Rural Water Department, Ministry of Water and Environment, Uganda. The late Dr. Eng. Paul Nyeko-Ogiramoi (who was supervised for his Ph.D. work by Prof. Patrick Willems of KU Leuven) appears as a co-author of this paper because, before passing on, he extracted and provided the CMIP3 data used in this study. Most importantly, this publication is a form of posthumous recognition to the late Dr. Eng. Paul Nyeko-Ogiramoi for his unforgettable kindness, readiness to share his profound knowledge, creditable commitment and love for scientific research while he was alive. May the good Lord rest the late Paul's soul in eternal peace!

\section{References}

Adler RF, Huffman GF, Chang A, Ferraro R, Xie P-P, Janowiak J, Rudolf B, Schneider U, Curtis S, Bolvin D, Gruber A, Susskind J, Arkin P, Nelkin E (2003) The version-2 global precipitation climatology project (GPCP) monthly precipitation analysis (1979-present). J Hydrometeorol 4: 11471167. 
Akinsanola AA, Ogunjobi KO, Gbode IE, Ajayi VO (2015) Assessing the capabilities of three regional climate nodels over CORDEX Africa in simulating West African summer Monsoon precipitation. Adv Meteorol 2016(Article ID 935431): 1-13, DOI:10.1155/2015/935431

Almasi P, Soltani S (2017) Assessment of the climate change impacts on flood frequency (case study: Bazoft Basin, Iran). Stoch Environ Res Risk Assess 31(5): 1171-1182.

Anyah RO, Semazzi FHM, Xie L (2006) Simulated physical mechanisms associated with climate variability over Lake Victoria basin in East Africa. Mon. Weather Rev 134: 3588-3609.

Bhatthacharya RN, Gupta VK, Waymire EC (1983) The Hurst effect under trends. J Appl Probab 20: 649-662.

Batisani N, Yarnal B (2010) Rainfall variability and trends in semi-arid Botswana: Implications for climate change adaptation policy. Appl Geogr 30: 483-489.

Camberlin P (2009) Nile Basin Climates, in: The Nile: Origin, Environments, Limnology and Human Use, Monographiae Biologicae, vol. 89, edited by: Dumont, H. J., Springer, Dordrecht, 307-333.

Ciu T, Yang T, Xu C-Y, Shao Q, Wang X, Li Z (2018) Assessment of the impact of climate change on flow regime at multiple temporal scales and 
potential ecological implications in an alpine river. Stoch Environ Res Risk Assess 32(6): 1849-1866.

DDC (2015) What is a GCM? Available online via the link: http://www.ipccdata.org/guidelines /pages/gcm_guide.html (accessed 17.04.15.).

Dosio A, Panitz H-J (2016) Climate change projections for CORDEX-Africa with COSMO-CLM regional climate model and differences with the driving global climate models. Clim Dyn 46(5-6): 1599-1625

Evans TE (1996) The effects of changes in the world hydrological cycle on availability of water resources. In: Global Climate Change and Agricultural Production: Direct and Indirect Effects of Changing Hydrological Pedological and Plant Physiological Processes (edited by Bazzaz F. \& Sombroek W.), Chapter 2. FAO and John Wiley, Chichester, West Sussex, UK.

Fraedrich K (1972) A simple climatological model of the dynamics and energetics of the nocturnal circulation at lake Victoria. Q J Royal Meteorol Soc 98: 332-335.

Funk C, Nicholson SE, Landsfeld M, Klotter D, Peterson P, Harrison L (2015) The Centennial Trends Greater Horn of Africa precipitation dataset. Dryad, DOI:10.5061/dryad.nk780 (2015)

Ghanmi H, Bargaoui Z, Mallet C (2013) Investigation of the fractal dimension of rainfall occurrence in a semi-aridMediterranean climate. Hydrol Sci J 58(3): 483-497.

Gupta VK, Waymire E (1990) Multiscaling properties of spatial rainfall and river flow distributions. J Geophys Res 95 (D3): 1999-2009. 
Harris I, Jones PD, Osborn TJ, Lister DH (2014) Updated high-resolution grids of monthly climatic observations-the CRU TS3.10 dataset. Int J Climatol 34: 623-642.

Hoerling M, Hurrell J, Eischeid J, Phillips A (2006) Detection and attribution of twentieth-century Northern and Southern African rainfall change. J Clim 19(16): 3989-4008.

Huffman GJ, Bolvin DT, Nelkin EJ, Wolff DB (2007) The TRMM

Multisatellite Precipitation Analysis (TMPA): Quasi-global, multiyear, combined-sensor precipitation estimates at fine scales. J Hydrometeorol 8: $38-55$.

Hurst HE (1951) Long-term storage capacity of reservoirs. Trans Am Soc Civil Eng 116: 770-799.

Indeje M, Semazzi FHM, Ogallo LJ (2000) ENSO signals in East African rainfall seasons. Int J Climatol 20: 19-46.

IPCC (2013) Climate Change 2013: The Physical Scien.ce Basis. Contribution of Working Group I to the Fifth Assessment Report of the IPCC.

Cambridge University Press, Cambridge, United Kingdom and New York, USA. 1535pp. 
James R, Washington R, Jones R (2015) Process-based assessment of an ensemble of climate projections for West Africa. J. Geophys Res Atmos 120: 1221-1238, DOI:10.1002/2014JD022513

Kantelhardt JW, Zschiegner SA, Bunde EK, Havlin S, Bunde A, Stanley HE (2002) Multifractal detrended fluctuation analysis of nonstationary time series. Physica A 316: 87-114.

Kaptué AT, Hanan NP, Prihodko L, Ramirez JA (2015) Spatial and temporal characteristics of precipitation in Africa: Summary statistics for temporal downscaling. Water Resour Res 51: 2668-2679.

Kerkhoven E, Gan TY (2011) Unconditional uncertainties of historical and simulated river flows subjected to climate change. J Hydrol 396: 113-127.

Kiely G, Ivanova K (1999) Multifractal Analysis of Hourly Precipitation. Phys Chem Earth (B) 24(7): 781-786.

Kim J, Ivanov VY, Fatichi S (2016) Climate change and uncertainty assessment over a hydroclimatic transect of Michigan. Stoch Environ Res Risk Assess 30(3): 923-944.

Kirtman B, Pirani A (2008) WCRP Position Paper on Seasonal Prediction, WCRP Informal Report No. 3/2008 ICPO Publication No. 127, available at http://wcrp.wmo.int/documents/WCRP_SeasonalPrediction_PositionPaper_ Feb2008.pdf [accessed: 2008].

Klemeš V (1974) The Hurst phenomenon: a puzzle? Wat Resour Res 10(4): $675-688$.

Klemeš V (1986) Operational testing of hydrological simulation models. Hydrol Sci J 31(1):13-24. 
Knutti R, Sedláček J (2012) Robustness and uncertainties in the new CMIP5 climate model projections. Nat Clim Change 3(4): 369-373.

Kolmogorov AN (1940) Wienersche Spiralen und Einige Andere Interessante Kurven in Hilbertschen Raum. Doklady Akademii nauk URSS 26: 115-118.

Koutsoyiannis D (2000) The Hurst phenomenon and fractional Gaussian noise made easy. Hydrol Sci J 47(4): 573-595.

Koutsoyiannis D (2003a) Climate change, the Hurst phenomenon, and hydrological statistics. Hydrol Sci J 48: 3-24.

Koutsoyiannis D (2003b) Internal report. Available online via the link http://www.itia.ntua.gr/getfile/537/2/2003HSJHurstSuppl.pdf (accessed $10^{\text {th }}$ August, 2017).

Koutsoyiannis D (2011) Hurst-Kolmogorov dynamics and uncertainty. J Am Water Res Ass 47(3): 481-495.

Li X, Wangm X, Babovic V (2018) Analysis of variability and trends of precipitation extremes in Singapore during 1980-2013. Int J Climatol 38(1): 125-141.

Lu J, Delworth TL (2005) Oceanic forcing of the late 20th century Sahel drought. Geophys Res Lett 32 L22706, DOI:10.1029/2005GL023316. 
MacKellar N, New M, Jack C (2014) Observed and modelled trends in rainfall and temperature for South Africa: 1960-2010. S Afr J Sci 110(7/8), Art. \#2013-0353, 13 pages, DOI:10.1590/sajs.2014/20130353

Maidment RI, Allan RP, Black E (2015) Recent observed and simulated changes in precipitation over Africa. Geophys Res Lett 42: 8155-8164.

Meehl GA, Covey C, Delworth T, Latif M, Mcavaney B, Mitchell JFB, et al. (2007) The WCRP CMIP3 multimodel dataset climate change research: a new era in climate change research. Bull Amer Meteor Soc 88: 1382-1394.

Meseguer-Ruiz O, Cantos JO, Sarricolea P, Martín-Vide J (2017) The temporal fractality of precipitation in mainland Spain and the Balearic Islands and its relation to other precipitation variability indices. Int J Climatol 37: 849_ 860.

Mohammed R, Scholz M, Nanekely MA, Mokhtari Y (2018) Assessment of models predicting anthropogenic interventions and climate variability on surface runoff of the Lower Zab River. Stoch Environ Res Risk Assess 32(1): 223-240.

Mukabana JR, Piekle RA (1996) Investigating the influence of synoptic-scale monsoonal winds and mesoscale circulations on diurnal weather patterns over Kenya using a mesoscale numerical model. Mon Wea Rev 124: 224244.

Nakicenovic N, Alcamo J, Davis G, de Vries B, Fenhann J, Gaffin S, et al. (2000) Special Report on Emissions Scenarios: A Special Report of Working Group III of the Intergovernmental Panel on Climate Change. Cambridge University Press, Cambridge, UK. 599 pp. available online via 
the link: http://www.grida.no/climate/ipcc/emission/index.htm (accessed: 16.04.2015.)

Nicholson SE (1996) A review of climate dynamics and climate variability in Eastern Africa, in: The Limnology, Climatology and Paleoclimatology of the East African Lakes, edited by: Johnson TC, Odada, EO, Gordon and Breach, Amsterdam, the Netherlands, pp 25-56.

Nicholson NE (2000)The nature of rainfall variability over Africa on time scales of decades to millenia. Glob Planet Change 26: 137-158.

Nkiaka E, Nawaz NR, Lovett JC (2017) Analysis of rainfall variability in the Logone catchment, Lake Chad basin. Int J Climatol 37(9): 3553-3564.

Novella NS, Thiaw WM (2013) African rainfall climatology version 2 for famine early warning systems. J Appl Meteorol Climatol 52(3): 588-606.

Nyeko-Ogiramoi P, Willems P, Mutua F, Moges SA (2012a) An elusive search for regional flood frequency estimates in the River Nile basin. Hydrol Earth Syst Sci 16: 3149-3163.

Nyeko-Ogiramoi P, Willems P, Ngirane-Katashaya G, Ntegeka V (2012b) Nonparametric statistical downscaling of precipitation from global climate models. In: Druyan, L. (Ed.), Climate Models. InTech Europe, University Campus STeP Ri. Slavka Krautzeka, Croatia, pp. 109-136. ISBN:978-95351-0135-2. 
Oguntunde PG, Lischeid G, Abiodun BJ (2017) Impacts of climate variability and change on drought characteristics in the Niger River Basin, West Africa. Stoch Environ Res Risk Assess 32(4): 1017-1034.

Okeyo AE (1987) The influence of lake Victoria on the convective activities over the Kenya highlands. J Meteorol Soc Japan 65, 689-695.

Onyutha C, Willems P (2015) Uncertainty in calibrating generalised Pareto distribution to rainfall extremes in Lake Victoria basin. Hydrol Res 46(3): 356-376.

Onyutha C, Tabari H, Rutkowska A, Nyeko-Ogiramoi P, Willems P (2016) Comparison of different statistical downscaling methods for climate change rainfall projections over the Lake Victoria basin considering CMIP3 and CMIP5. J Hydro-environ Res 12: 31-45.

Onyutha C, Willems P (2017) Space-time variability of extreme rainfall in the River Nile basin. Int J Climatol 37(4): 4915-4924

Onyutha C (2018a) Trends and variability in African long-term precipitation. Stoch Environ Res Risk Assess, DOI: 10.1007/s00477-018-1587-0

Onyutha C (2018b) African food insecurity in a changing climate: The roles of Science and Policy. Food Energy Sec (under review after minor revision).

Onyutha C, Willems P (2018) Investigation of flow-rainfall co-variation for catchments selected based on the two main sources of River Nile. Stoch Environ Res Risk Assess 32: 623-641.

Onyutha C (2017) On rigorous drought assessment using daily time scale: Nonstationary frequency analyses, revisited concepts, and a new method to yield non-parametric indices. Hydrology 4: 48. DOI: 10.3390/hydrology4040048 
Onyutha C (2016a) Identification of sub-trends from hydro-meteorological series. Stoch Env Res Risk Assess 30: 189-205.

Osman OE, Hastenrath SL (1969) On the synoptic climatology of summer rainfall over Central Sudan. Archiv für Meteorologie, Geophysik und Bioklimatologie, Ser. B 17: 297-324.

Ouyang F, Zhu Y, Fu G, Lü H, Zhang A, Yu Z, Chen X (2015) Impacts of climate change under CMIP5 RCP scenarios on streamflow in the Huangnizhuang catchment. Stoch Environ Res Risk Assess 29(7): 17811795.

Rangarajan G, Sant DA (1997) A climate predictability index and its applications. Geophys Res Lett 24: 1239-1242.

Rangarajan G, Sant DA (2004) Fractal dimensional analysis of Indian climatic dynamics. Chaos Soliton Fract 19: 285-291.

Roushangar K, Nourani V, Alizadeh F (2018) A multiscale time-space approach to analyze and categorize the precipitation fluctuation based on the wavelet transform and information theory concept. Hydrol Res DOI:10.2166/nh.2018.143

Rutkowska A, Willems P, Onyutha C, Młocek W (2017) Temporal and spatial variability of extreme river flow quantiles in the Upper Vistula River basin, Poland. Hydrol Process 31(7): 1510-1526. 
Sheffield J, Goteti G, Wood EF (2006) Development of a 50-year highresolution global dataset of meteorological forcings for land surface modeling. J Clim 19(13): 3088-3111.

Solomon S, Qin D, Manning M, Chen Z, Marquis M, Averyt KB, Tignor M, Miller HL (Eds.) (2007) Climate Change 2007: The Physical Science Basis. Cambridge Univ. Press, Cambridge, 996 pp.

Sun F, Roderick ML, Farquhar GD (2018) Rainfall statistics, stationarity, and climate change. Proc Natl Acad Sci USA 115 (10): 2305-2310.

Taylor KE, Stouffer RJ, Meehl GA (2012) An overview of CMIP5 and the experiment design. B Am Meteorol Soc 93: 485-498.

Tessier Y, Lovejoy S, Hubert P, Schertzer D, Pecknold S (1996) Multifractal analysis and modelling of rainfall and river flows and scaling, causal transfer functions. J Geophys Res 101 (D21), 26427-26440

Trewartha GT (1981) The earth’s problem climates. Univ. of Wisconsin Press, Madison, WI, 371pp.

Washington R, James R, Pearce H, Pokam WM, Moufouma-Okia W (2013) Congo basin rainfall climatology: Can we believe the climate models? Philos Trans R Soc Lond Ser B DOI:10.1098/rstb.2012.0296

Williams AP, Funk C (2011) A westward extension of the warm pool leads to a westward extension of the Walker circulation, drying eastern Africa. Clim Dyn 37(11-12): 2417-2435.

World Meteorological Organization (1988), Analyzing Long Time Series of Hydrological Data with Respect to Climate Variability. WCAP Report No 3, 1988. WMO/TD-NO 224. 
Wu Y, Zhong P, Xu B, Zhu F, Ma B (2017) Changing of flood risk due to climate and development in Huaihe River basin, China. Stoch Environ Res Risk Assess 31(4): 935-948.

Wu Y, Liu S, Yan W, Xia J, Xiang W, Wang K, Luo Q, Fu W, Yuan W (2016) Climate change and consequences on the water cycle in the humid Xiangjiang River Basin, China. Stoch Environ Res Risk Assess 30(1): 225235.

Yu Z-G, Leung Y, Chen YD, Zhang Q, Anh V, Zhou Y (2014) Multifractal analyses of daily rainfall time series in Pearl River basin of China. Physica A 405: 193-202.

Zhang Q, Xu C-Y, Zhang Z, ChenYD, Liu C-L (2008) Spatial and temporal variability of precipitation maxima during 1960-2005 in the Yangtze River basin and possible association with large-scale circulation. J Hydrol 353: 215-227. 


\section{Appendix A. Further details on the climate models}

Table A1. Information on selected climate models of the CMIP3 simulations

\begin{tabular}{cll}
\hline SNo & \multicolumn{1}{c}{ CMIP3 } & \multicolumn{1}{c}{ Institution } \\
\hline 1 & GISS-AOM & NASA / Goddard Institute for Space Studies \\
2 & BCCR-BCM2.0 & Bjerknes Centre for Climate Research \\
3 & CGCM3.1(T47) & Canadian Centre for Climate Modelling \& Analysis \\
4 & CGCM3.1(T63) & \\
5 & GFDL-CM2.0 & US Dept. of Commerce / NOAA / Geophysical Fluid \\
6 & GFDL-CM2.1 & Dynamics Laboratory \\
7 & INM-CM3.0 & Institute for Numerical Mathematics \\
8 & MPI- ECHAM4-OM & Max Planck Institute for Meteorology \\
9 & ECHAM5/MPI-OM & \\
\hline
\end{tabular}


Meteorological Institute of the University of Bonn,

10 ECHO-G

11 MIROC3.2(hires)

12 MIROC3.2(medres)

13 CSIRO-MK3.0

14 CSIRO-MK3.5a
Meteorological Research Institute of KMA, and Model and Data group.

Center for Climate System Research

(The University of Tokyo), National Institute for

Environmental Studies, and Frontier

Research Center for Global Change (JAMSTEC)

CSIRO (Commonwealth Scientific and Industrial

Research Organisation) Atmospheric Research

Table A2. Information on selected climate models of the CMIP5 simulations

\begin{tabular}{|c|c|c|}
\hline SNo & CMIP5 & Institution \\
\hline 1 & BCC-CSM1.1-M & $\begin{array}{l}\text { Beijing Climate Centre, China Meteorological } \\
\text { Administration }\end{array}$ \\
\hline 2 & BNU-ESM & $\begin{array}{l}\text { College of Global Change and Earth System Science, } \\
\text { Beijing Normal University }\end{array}$ \\
\hline 3 & CANESM2 & Canadian Centre for Climate Modelling and Analysis \\
\hline 4 & CSIRO-MK3.6.0 & $\begin{array}{l}\text { Commonwealth Scientific and Industrial Research } \\
\text { Organisation in collaboration with the Queensland } \\
\text { Climate Change Centre of Excellence }\end{array}$ \\
\hline 5 & CNRM-CM5 & $\begin{array}{l}\text { Centre National de Recherches } \\
\text { Météorologiques/Centre Européen de Recherche et } \\
\text { Formation Avancée en Calcul Scientifique }\end{array}$ \\
\hline 6 & FGOALS-G2 & $\begin{array}{l}\text { LASG, Institute of Atmospheric Physics, Chinese } \\
\text { Academy of Sciences; and CESS, Tsinghua University }\end{array}$ \\
\hline $\begin{array}{l}7 \\
8\end{array}$ & $\begin{array}{l}\text { GFDL_CM } \\
\text { GFDL-ESM2G }\end{array}$ & Geophysical Fluid Dynamics Laboratory \\
\hline
\end{tabular}




\begin{tabular}{|c|c|c|}
\hline 9 & IPSL-CM5A-MR & Institut Pierre-Simon Laplace \\
\hline 10 & MIROC-ESM & Atmosphere and Ocean Research Institute (The \\
\hline \multirow{3}{*}{11} & \multirow{3}{*}{ MIROC-ESM-CHEM } & University of Tokyo), National Institute for \\
\hline & & Environmental Studies, and Japan Agency for Marine- \\
\hline & & Earth Science and Technology \\
\hline 12 & MPI-ESM-LR & \multirow{2}{*}{ Max Planck Institute for Meteorology (MPI-M } \\
\hline 13 & MPI-ESM-MR & \\
\hline 14 & MRI-CGCM3 & Meteorological Research Institute \\
\hline
\end{tabular}

Table A3. Information on selected climate models of the CORDEX simulations

\begin{tabular}{clll}
\hline SNo & \multicolumn{1}{c}{ CORDEX } & \multicolumn{1}{c}{ RCM } & \multicolumn{1}{c}{ GCM } \\
\hline 1 & CCLM4-8-17-MPI-ESM-LR & CCLM4-8-17 & MPI-ESM-LR \\
2 & CCLM4-8-17-CNRM-CM5 & CCLM4-8-17 & CNRM-CM5 \\
3 & CRCM5-MPI-ESM-LR & CRCM5-MPI & MPI-ESM-LR \\
4 & CRCM5-CanESM2 & CRCM5 & CanESM2 \\
5 & HIRHAM5-NorESM1-M & HIRHAM5 & NorESM1-M \\
6 & RACMO22T -EC-EARTH & RACMO22T & EC-EARTH \\
7 & RACMO22T -HadGEM2-ES & RACMO22T & HadGEM2-ES \\
8 & RCA4-MIROC5 & RCA4 & MIROC5 \\
9 & RCA4-HadGEM2-ES & RCA4 & HadGEM2-ES \\
10 & RCA4-GFDL-ESM2M & RCA4 & GFDL-ESM2M \\
11 & RCA4-CM5A-MR & RCA4 & CM5A-MR \\
12 & RCA4-CSIRO-Mk3-6-0 & RCA4 & CSIRO-Mk3-6-0 \\
13 & REMO2009-CM5A-LR & REMO2009 & CM5A-LR \\
14 & REMO2009-MPI-ESM-LR & REMO2009 & MPI-ESM-LR \\
\hline
\end{tabular}

Note: the institutions for the GCMs are as those in Table A2 except for:

CanESM2 : Canadian Centre for Climate Modelling and Analysis

NorESM1-M : Norwegian Climate Centre

HadGEM2-ES: Met Office Hadley Centre

GFDL-ESM2M: Geophysical Fluid Dynamics Laboratory

MIROC5 : the same institution with MIROC-ESM 
Appendix B. Ensemble mean projections for the CV of MDS, MWS and daily rainfall 

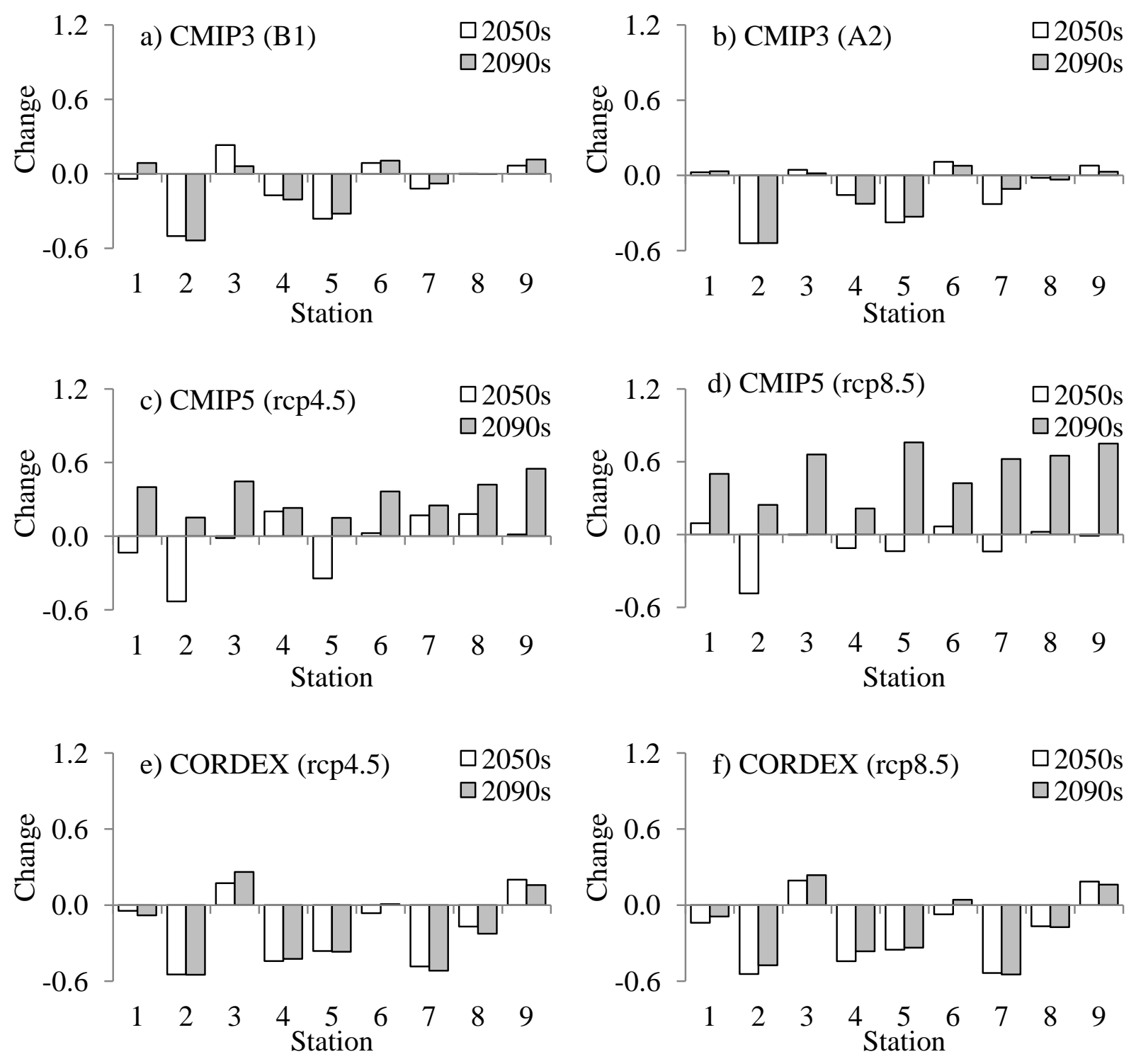

Appendix B1 Ensemble mean changes in the CV of MDS for (a-b) CMIP3, (c-

d) CMIP5, and (e-f) CORDEX RCM simulations over the periods 2050s and 2090s 


\section{KU LEUVEN}
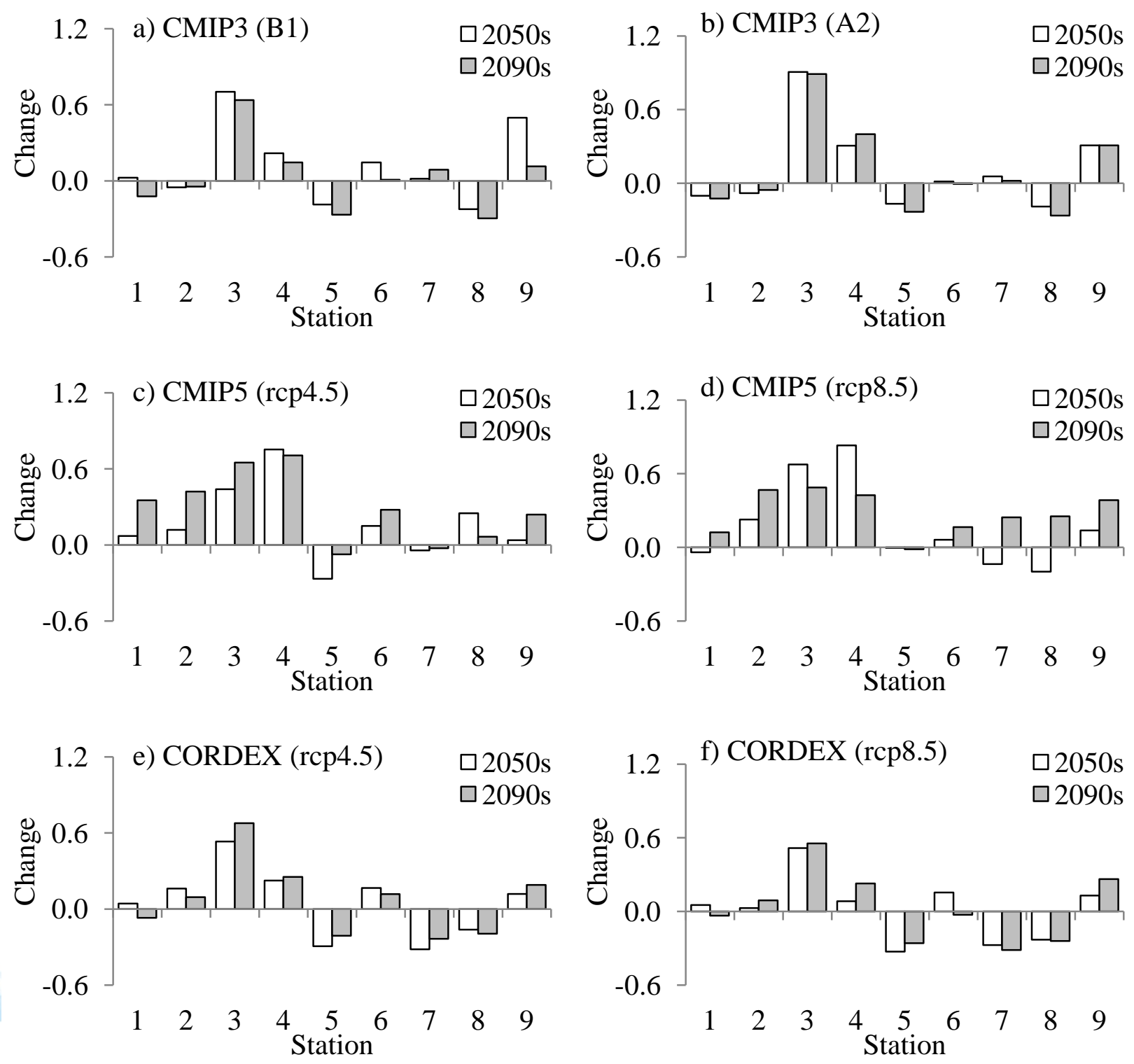

Appendix B2 Ensemble mean changes in the CV of MWS for (a-b) CMIP3, (c-

d) CMIP5, and (e-f) CORDEX RCM simulations over the periods 2050s

and 2090s 

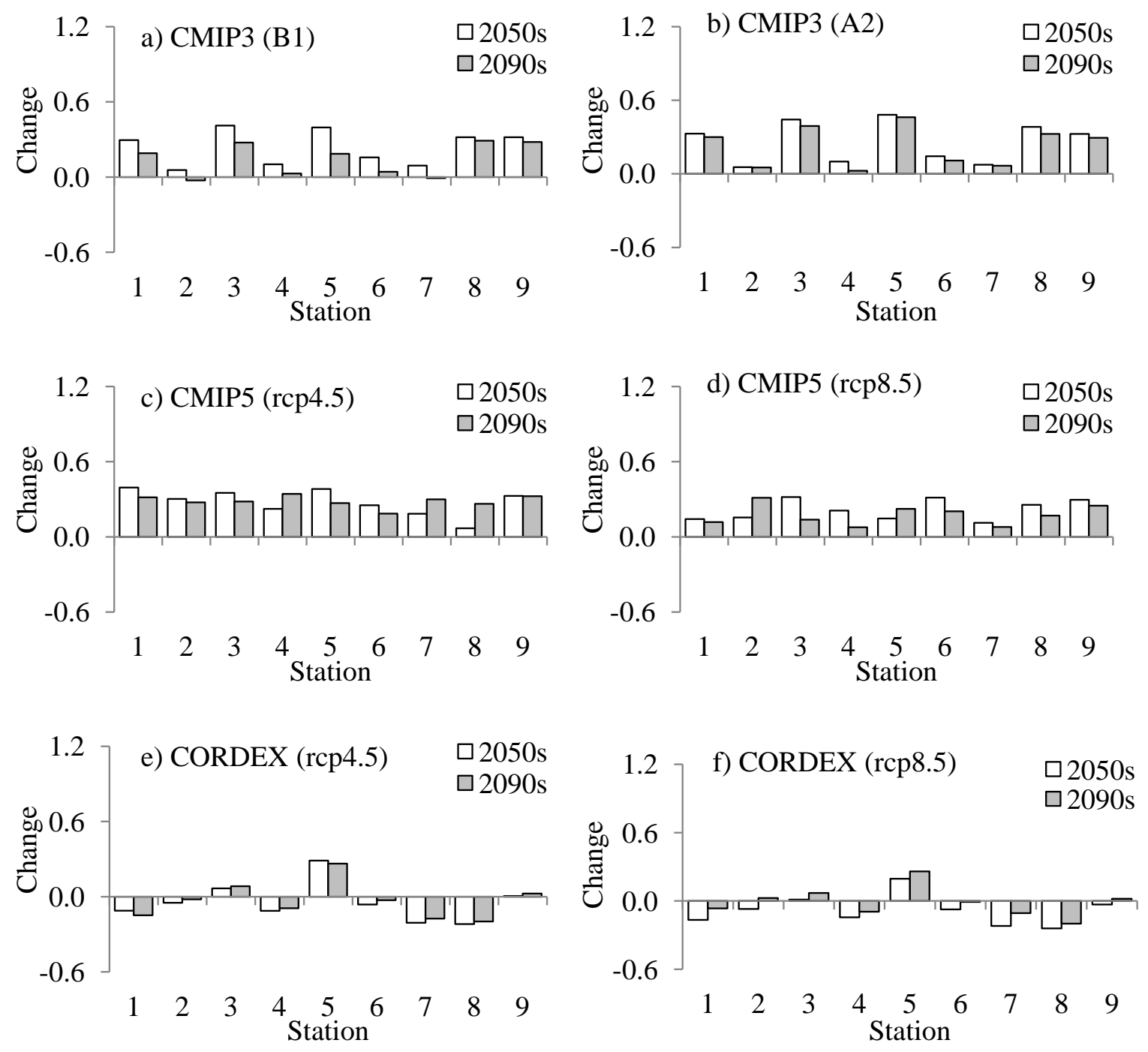

Appendix B3 Ensemble mean changes in the CV of daily rainfall for (a-b)

CMIP3, (c-d) CMIP5, and (e-f) CORDEX RCM simulations over the periods 2050s and 2090s 